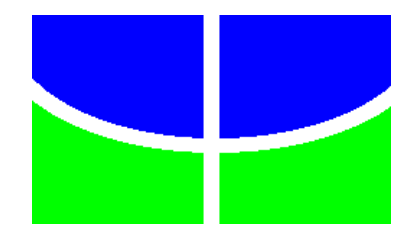

UNIVERSIDADE DE BRASÍLIA

Centro de Excelência em Turismo

Pós-Graduação Lato Sensu

Curso de Especialização em Qualidade em Alimentos

\title{
PRÁTICAS ALIMENTARES DOS ESTUDANTES DE PÓS-GRADUAÇÃO DO CET - UNB
}

\author{
Joseane Lima Ferreira Lelis
}

\section{Orientadora: Dra. Raquel Botelho}

Monografia apresentada ao Centro de Excelência em Turismo - UNB como requisito parcial para obtenção de título de Especialista em Qualidade em Alimentos 
LELIS, Joseane Lima Ferreira

Práticas Alimentares dos Estudantes de Pós-Graduação do CET - UNB 36 páginas.

Monografia apresentada ao curso Especialização em Qualidade em Alimentos Universidade de Brasília. Centro de Excelência em Turismo. Brasília, 2009.

Área de concentração - Nutrição

Orientadora - $\operatorname{Prof}^{\mathrm{a}} \operatorname{Dr}^{\mathrm{a}}$ Raquel Botelho

1. Alimentação Saudável 2. Práticas Alimentares 3. Educação Alimentar. 


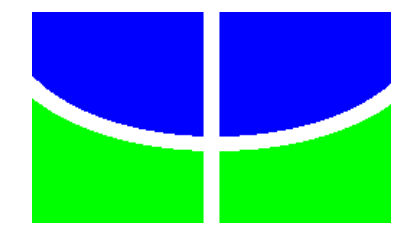

UNIVERSIDADE DE BRASÍLIA

Centro de Excelência em Turismo

Pós-Graduação Lato Sensu

Curso de Especialização em Qualidade em Alimentos

\author{
JOSEANE LIMA FERREIRA LELIS
}

\title{
PRÁTICAS ALIMENTARES DOS ESTUDANTES DE PÓS-GRADUAÇÃO DO CET - UNB
}

Monografia apresentada ao Centro de Excelência em Turismo - CET, da Universidade de Brasília, como requisito parcial à obtenção do grau de Especialista em Qualidade em Alimentos.

Aprovado em:

\footnotetext{
Prof $^{a}$ Dr $^{a}$. Raquel Braz Assunção Botelho Prof ${ }^{\mathrm{a}}$ Orientadora
}

Prof $^{\mathrm{a}}$ Dra $^{\mathrm{a}}$. Karin Eleonora Sávio de Oliveira

Prof $^{\mathrm{a}}$ Dra $^{\mathrm{a}}$. Sandra Fernandes Arruda

BRASÍLIA - DF

2009 
Aos meus pais, Nelson e Cida pelo amor incondicional

Ao Marcelo pelo apoio e incentivo Aos meus irmãos Cristian e Rogério pelo carinho 


\section{AGRADECIMENTOS}

A Deus por me conceder a vida.

A professora Doutora Raquel Botelho pela valiosa orientação e pelos ensinamentos transmitidos.

A Christiane Lopes, pela amizade que construímos durante o curso.

A todos os professores.

Aos colegas de curso.

A todos que eu não tenha mencionado e que colaboraram na realização desta pesquisa, os meus mais profundos agradecimentos. 
"Há um tempo em que é preciso abandonar as roupas usadas que já têm a forma do nosso corpo e esquecer os nossos caminhos que nos levam sempre aos mesmos lugares. É o tempo da travessia e, se não ousarmos fazê-la, teremos ficado, para sempre, à margem de nós mesmos"

Fernando Pessoa 


\section{RESUMO}

LELIS, Joseane Lima Ferreira. Práticas Alimentares dos Estudantes de Pós-Graduação do CET - UNB. 2009. 36 p. Monografia - Programa de Pós-Graduação em Qualidade em Alimentos - Universidade de Brasília. Centro de Excelência em Turismo. Brasília, 2009.

Práticas alimentares saudáveis devem ser sempre incentivadas visando o consumo de alimentos que atendam as necessidades nutricionais, respeitando a cultura de cada indivíduo. Uma alimentação inadequada com baixo consumo de frutas e hortaliças, por exemplo, pode desencadear doenças crônicas não transmissíveis (DCNT). São incluídas nesse grupo doenças cardíacas coronarianas, doenças cérebro-vasculares, vários tipos de cânceres, diabetes melito, cálculos biliares, cáries dentárias, distúrbios gastrointestinais e várias doenças ósseas e de articulações. Este trabalho objetivou avaliar as práticas alimentares dos discentes do Centro de Excelência em Turismo - CET da UnB sobre alimentação saudável. Para coleta de dados foram aplicados 47 formulários em discentes de pós-graduação matriculados no $2^{\circ}$ semestre de 2008 no Centro de Excelência em Turismo - CET, localizado na Universidade de Brasília UNB. Participaram da amostra alunos matriculados nos cursos de: Qualidade em Alimentos, Gestão de Negócios em Turismo e Gastronomia e Segurança Alimentar. Quanto à adoção de práticas alimentares saudáveis, o resultado mais satisfatório foi observado na amostra de discentes do curso de Gastronomia e Segurança Alimentar, embora o que prevaleceu nesse curso e nos demais foi a não adequação da recomendação do consumo diário estabelecida pelo Guia Alimentar (Brasil, 2006): Como ter uma Alimentação Saudável, usado como referência para essa pesquisa. Esse resultado pode ser decorrente do fato do curso de Gastronomia e Segurança Alimentar contar com 60\% de nutricionistas em seu quadro de alunos. Embora a maior parte dos discentes do curso de Qualidade em Alimentos também serem de nutricionistas, $56 \%$, essa amostra não obteve resultados adequados na maioria das questões. Como hábitos e práticas demoram um tempo para serem alterados, pode ser que o tempo de formação dos nutricionistas seja uma causa para diferença, ou até mesmo, a não preocupação desse grupo com a dieta saudável. Esse resultado sugere que para possibilitar a adoção de hábitos e práticas alimentares saudáveis é importante ampliar as atividades educativas junto à população com base em informações científicas e em políticas públicas. Palavras-chave: Alimentação Saudável, Práticas Alimentares, Educação Alimentar 


\begin{abstract}
LELIS, Joseane Lima Ferreira. Práticas Alimentares dos Estudantes de Pós-Graduação do CET - UNB. 2009. 36 p. Monografia - Programa de Pós-Graduação em Qualidade em Alimentos - Universidade de Brasília. Centro de Excelência em Turismo. Brasília, 2009.

Healthy eating habits should always be encouraged to the consumption of foods that meet nutritional needs, while respecting the culture of each individual. An inadequate supply of low consumption of fruits and vegetables, for example, can trigger chronic diseases later (DCNT). Are included in this group coronary heart disease, cerebral-vascular disease, several types of cancers, diabetes mellitus, gallstones, dental caries, gastrointestinal disorders and various diseases of bone and joints. This study aimed to evaluate the eating habits of students of the Center for Excellence in Tourism - the UnB CET on healthy eating. For data collection forms were used in 47 post-graduate students enrolled in the 2nd half of 2008 at the Center for Excellence in Tourism - CET, located at the University of Brasilia - UNB. Part of the sample of students enrolled in courses: Quality in Food, Business in Tourism Management and Food and Food Security. As the adoption of healthy eating habits, the most satisfactory result was observed in the sample of students of the course in Food and Food Security, but what prevailed in this course and the other was the inadequacy of the recommendation of daily intake established by the Food Guide (Brazil , 2006): How to have a healthy diet, used as reference for this research. This result may be due to the fact that the course of Gastronomy and Food Security have $60 \%$ of nutritionists in your part of students. While most students in the course of Quality Foods are also of nutritionists, 56\%, this sample did not achieve adequate results in most of the issues. As habits and practices take time to be changed, it may be that time of training of nutrition is a cause for difference, or even the group with no concern that the healthy diet. This result suggests that to enable the adoption of healthy dietary habits and practices is important to expand the educational activities among the population on the basis of scientific information and publicpolicies.
\end{abstract} Key words: healthy eating, eating habits, Nutrition Education 


\section{SUMÁRIO}

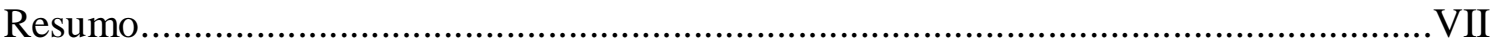

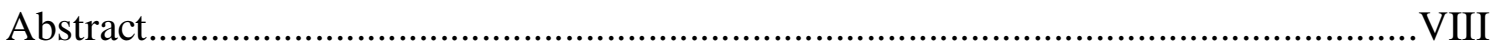

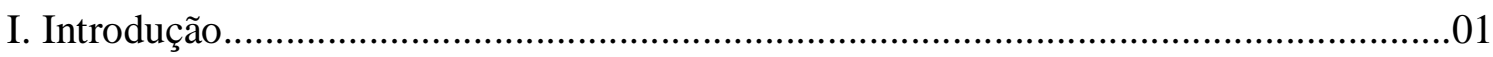

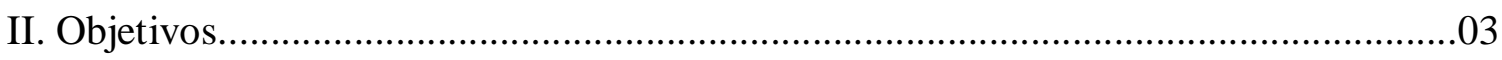

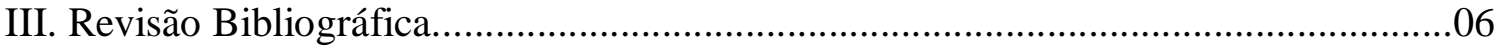

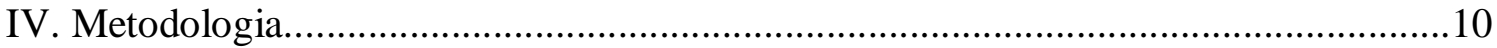

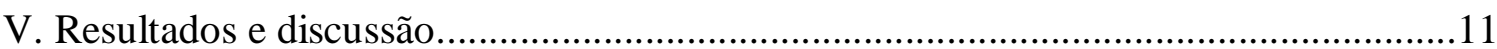

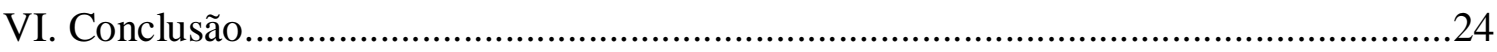

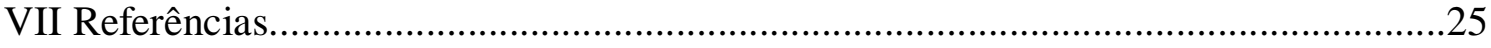

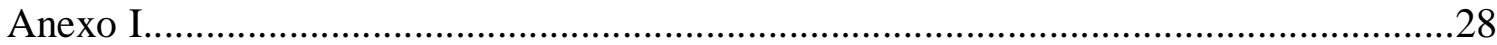

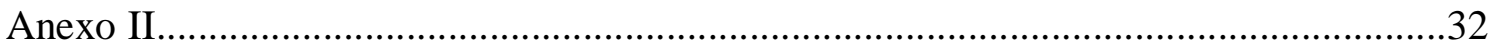

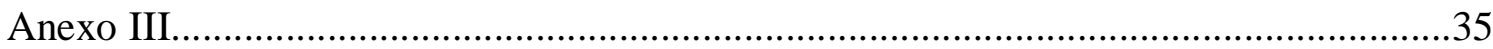




\section{I-INDRODUÇÃO}

A escolha alimentar humana está fundamentada, por um lado, na condição onívora do homem, isto é, alimentar-se de uma grande variedade de alimentos tanto de origem vegetal como animal e, por outro lado, por diversos outros fatores que irão influenciar o indivíduo nessa decisão (BRASIL, 2006; JOMORI, PROENÇA, CALVO, 2008).

Para Garcia (2003), o comensal urbano e atual se caracteriza pela falta de tempo para o preparo e consumo de alimentos, pela presença de produtos gerados com novas tecnologias, pela ampla opção de itens alimentares, pelos deslocamentos das refeições de casa para restaurantes e lanchonetes [...]. Aliado a isso segundo Tardido e Falcão (2006), a presença feminina no trabalho fora de casa pode contribuir para as reais mudanças no preparo de alimentos na esfera domiciliar e no perfil de compra de alimentos fora do domicilio.

Desse modo segundo Garcia (2003), influenciadas pelos avanços tecnológicos na indústria de alimentos e pela globalização, as práticas alimentares atuais têm sido objeto de preocupação das ciências da saúde desde que os estudos epidemiológicos passaram a relacionar algumas doenças crônicas associadas à alimentação.

De forma mundial a modernização está provocando mudanças nos padrões de dieta e de consumo dos alimentos (POUBEL, 2006). Para Mondini e Monteiro (1994), apesar do consumo alimentar ser um tema pouco avaliado no Brasil, pesquisas apontam para mudanças no padrão alimentar do brasileiro onde pode perceber um aumento no consumo da alimentação industrializada.

É preciso lembrar que o comportamento alimentar é complexo, incluindo determinantes externos e internos ao sujeito (GARCIA, 2003). Para Botelho (2006), a maioria das pessoas recusa alimentos que não fazem parte da sua cultura e que não está acostumada a consumir. A autora diz que as aptidões para a identificação de determinados alimentos delineiam os hábitos alimentares. Para Ginani (2004), o que determina as preferências alimentares de uma população são aspectos variados como: fatores econômicos, sociais, políticos, agrários e religiosos. De acordo com a autora somam-se episódios precisos, como influências específicas, que podem ser categórico na formação do hábito alimentar, respeitando as limitações sensoriais de cada povo.

A informação acima está de acordo com o Guia Alimentar (Brasil, 2006), ao destacar

que as práticas alimentares saudáveis devem ter como prioridade o resgate de hábitos alimentares regionais próprios ao consumo de alimentos, in natura, e de elevado valor nutritivo, como frutas, hortaliças, grãos integrais, leguminosas, sementes e castanhas. 
Portanto, segundo Oliveira (2007), o problema da alimentação no Brasil é a falta de conhecimento e a falta de instrução a respeito do assunto. É fundamental buscar informação e orientação para se ter mudança de comportamento no que diz respeito à alimentação. É o que mostram dados de uma pesquisa realizada com universitários entre 18 a 36 anos, onde embora a distribuição de macronutrientes estivesse de acordo com a dieta, o consumo de fibras, energia, vitaminas e minerais era deficiente e a ingestão de colesterol elevada (RAMOS, 2005).

Assim, existem poucos estudos que avaliam as práticas alimentares do comensal sobre sua alimentação. Como afirma Oliveira (2007), ao dizer que é importante que os estudos sobre consumo de alimentos e sobre indicadores de estado nutricional abranjam a percepção, os conhecimentos e os conceitos sobre alimentação. 


\section{II-OBJETIVOS}

\section{Objetivo Geral:}

Avaliar as práticas alimentares de uma amostra de discentes do Centro de Excelência em Turismo - CET da UnB.

\section{Objetivos Específicos:}

Avaliar os conhecimentos sobre práticas alimentares em alunos do CET, por meio da aplicação de formulário disponibilizado no Guia Alimentar (Brasil, 2006);

Identificar aspectos que definam alimentação saudável para os discentes;

Verificar a freqüência dos diferentes grupos alimentares na dieta de estudantes do CET. 


\section{III- REVISÃO BIBLIOGRÁFICA}

Em uma alimentação saudável deve fazer parte da dieta diária todos os grupos de alimentos onde, água, carboidratos, lipídios, proteínas, fibras, vitaminas e minerais são indispensáveis ao bom funcionamento do organismo (BRASIL, 2006).

Uma alimentação saudável, é aquela variada, acessível, harmônica em quantidade e qualidade, naturalmente colorida, segura sanitariamente e saborosa (BRASIL, 2005). Em função disso, de acordo com Mondini e Monteiro (1994), por meio de uma alimentação adequada em quantidade e qualidade, o organismo adquire a energia e os nutrientes necessários para o bom desempenho de suas funções e para a manutenção de um bom estado de saúde. Em uma alimentação saudável é importante estimular o consumo de alimentos regionais e de alto valor nutritivo como frutas, hortaliças, grãos integrais, leguminosas, sementes e castanhas (BRASIL, 2006).

Para o Guia Alimentar brasileiro (2006), aumentar o hábito de se consumir frutas e hortaliças é um grande desafio, uma vez que os níveis atuais estão muito abaixo do que é comprovadamente saudável, independentemente da renda, varia de $3 \%$ a $4 \%$ do valor energético total, entre os anos de 1974-2003.

De acordo com o Guia Alimentar brasileiro (2006, p.16), "uma alimentação saudável tem início com a prática do aleitamento materno exclusivo até os seis meses de idade e complementar até, pelo menos os dois anos, e se prolonga pela vida com adoção de bons hábitos alimentares".

O Ministério da Saúde (2006, p.17-23), elaborou uma proposta com os 10 passos para se ter uma alimentação saudável, sendo estes:

1. "Faça pelo menos três refeições (café-da-manhã, almoço e jantar) e dois lanches saudáveis por dia;

2. Inclua diariamente seis porções do grupo do cereais (arroz, milho, trigo, pães e massas), tubérculos como as batatas e raízes como a mandioca nas refeições. Dê preferência aos grãos integrais e aos alimentos na sua forma mais natural;

3. Coma diariamente pelo menos três porções de legumes e verduras como parte das refeições e três porções ou mais de frutas nas sobremesas e lanches;

4. Coma feijão com arroz todos os dias ou, pelo menos, 5 vezes por semana;

5. Consuma diariamente três porções de leite e derivados e uma porção de carnes, aves, peixes ou ovos;

6. Consuma, no máximo, uma porção por dia de óleos vegetais, azeite, manteiga ou margarina;

7. Evite refrigerantes e sucos industrializados, bolos, biscoitos doces e recheados e sobremesas como regra da alimentação;

8. Diminua a quantidade de sal na comida e retire o saleiro da mesa;

9. Beba pelo menos dois litros (seis a oito copos) de água por dia. Dê preferência ao consumo de água nos intervalos das refeições; 
10. Torne sua vida mais saudável. Pratique pelo menos 30 minutos de atividade física todos os dias e evite as bebidas alcoólicas e o fumo."

Sendo assim, mais do que formular proibições, uma proposta de uma dieta para a população brasileira deve englobar o resgate dos hábitos alimentares saudáveis próprios da comida brasileira e a identificação de alimentos, cujo consumo deva ser estimulado (SICHIERI; COITINHO; MONTEIRO; COUTINHO, 2000). Para Sloan (2005), é importante notar que, incentivar as pessoas a buscarem alimentos saudáveis é um convite a uma alimentação diferenciada e também à descoberta de determinados alimentos.

Deve-se notar, todavia, que a alimentação saudável não se descreve enquanto um conceito igual para todos, pois deve respeitar algumas características coletivas e individuais (PINHEIRO, 2005). De acordo com a autora, no entanto, identificam-se alguns princípios básicos que devem reger a relação entre as práticas alimentares e a promoção da saúde e a prevenção de doenças. Como mostra Assis e Nahas (1999) e Tardido e Falcão (2006), ao dizer que hábitos e práticas alimentares são construídos com base em determinações socioculturais, antropológicos, econômicos e psicológicos que envolvem o ambiente das pessoas.

\footnotetext{
"Sob o ponto de vista coletivo, uma alimentação saudável torna-se adequada quando também compreende aspectos relativos a percepção dos sujeitos sobre os modos de vida adequados, ou seja, quando se identifica com as expectativas dos diferentes grupos sociais, que compõe a sociedade. Para isso as dimensões de variedade, quantidade, qualidade e harmonia precisam associar-se aos padrões culturais, regionais, antropológicos e sociais das populações (PINHEIRO, 2005, p.3)."
}

Por sua vez, a escolha dos alimentos é um hábito natural movido por desejos tanto racionais como emocionais. A relação que uma pessoa estabelece com sua alimentação é causada por fatores ambientais e pessoais (PINHEIRO, 1999). As pessoas, ao alimentar-se, não buscam apenas suprir suas necessidades orgânicas de nutrientes. De acordo com seus valores culturais, sociais, afetivos, e sensoriais buscam cheiro, cor, textura e sabor nos alimentos (BRASIL, 2005).

Seguindo uma perspectiva mais ampla, com o avanço da pesquisa científica nenhuma cultura tradicional ou povo primitivo teve tantas dúvidas do que e como comer (AZEVEDO, 2003). Segundo o autor, junto com a industrialização e a tecnologia na fabricação dos alimentos está a incerteza na qualidade do produto final. Aliado a essa informação de acordo com Garcia (2003), a tendência para o consumo de alimentos de maior concentração calórica 
é crescente e promovida pela indústria de alimentos através da grande produção de alimentos saborosos, de alta densidade energética e de custo relativamente baixo.

Segundo Garcia (1997) e Sloan (2005), mudanças no estilo de vida, em específico o da urbanização, acarreta uma reorganização de valores e práticas que, seguramente, trazem consequiências no padrão alimentar gerando problemas relacionados com alimentação. Para Sloan (2005), as populações que vivem em cidades, além de serem menos ativas fisicamente, consomem uma quantidade muito maior de alimentos prontos, em casa e/ou em restaurantes. De acordo com Cota e Miranda (2006), mudança nos hábitos alimentares, proveniente da industrialização, tem introduzido um elevado consumo de alimentos refinados pobres em fibras alimentares, contidas em maior quantidade nas frutas, hortaliças e cereais integrais.

Com relação às praticas alimentares, é necessário buscar um maior entendimento do peso da alimentação fora do domicilio e do consumo de produtos industrializados e instantâneos pelos vários segmentos da sociedade (TARDIDO; FALCÃO, 2006). Se por um lado a praticidade resolve a falta de tempo da dona de casa no preparo das refeições, por outro traz consequiências negativas como: excesso de aditivos, padronização de gostos, aumento de populações obesas ou desnutridas e como uma das consequiências futuras a busca por regimes alimentares (ARAÚJO et al, 2005). Comumente, alimentos oferecidos em bares, cantinas e restaurantes tendem a ser mais ricos em gorduras e açúcares do que os alimentos consumidos diariamente em casa (BRASIL, 2006).

"O tempo na cidade provocou uma reorganização da rotina interna da família, mesmo quando a mulher não se encontra inserida no mercado de trabalho e dedica seu tempo exclusivamente às atividades domésticas. Comer em casa, nos grandes centros urbanos, não depende apenas de ter alguém que se ocupe do preparo da comida. A distância entre o local de trabalho e a casa, as dificuldades de deslocamento impostas pelo trânsito e o próprio ritmo da cidade, dificultam a execução das refeições no domicílio." (GARCIA, 1997, p.5).

A comida do tipo fast-food, por exemplo, considerada perigosa para a saúde, pelo excesso de gorduras, é também valorizada, por representar liberdade, prazer e modernidade (FREITAS; PENA, 2007). Para Bleil (1998, p.17), "o fast-food tornou-se assim uma alternativa rápida de refeição, porém na maior parte das vezes carecendo de aporte nutritivo". 
De acordo com o Guia Alimentar brasileiro (2006), a maior parte desses alimentos précozidos oferecidos em lanchonetes, bares e restaurantes são derivados de carne e apresentam alto teor de gordura, sal e açúcar.

Hoje em dia, as opções alimentares preferidas são aquelas que poupam o tempo disponível para se alimentar e que fornecem muitas calorias, pouco valor nutritivo, excesso de gorduras e açúcares, e são pobres em carboidratos complexos e fibras (KOEHNLEIN; SALADO; YAMADA, 2008).

Numa outra direção, para Gomes (2007), ao consumir uma variedade de frutas e hortaliças além de garantir uma adequada ingestão dos micronutrientes e das fibras, pode ajudar a substituir alimentos que possuem altas concentrações de gorduras saturadas ${ }^{1}$, açúcar e sal.

Segundo Bleil (1998), em alguns campos da sociedade, existe uma preocupação com a alimentação enquanto uma garantia de boa saúde. Essa informação está de acordo com Cervato et al. (2005), ao dizerem que no processo de envelhecimento a importância da alimentação é evidenciada por estudos epidemiológicos, clínicos e de intervenção, entre outros, que têm comprovado ligação entre o tipo de dieta e o surgimento de doenças crônicas não transmissíveis (DCNT). Segundo os autores, podem ser incluídas nesse grupo doenças cardíacas coronarianas, doenças cérebro-vasculares, vários tipos de cânceres, diabetes melito, cálculos biliares, cáries dentárias, distúrbios gastrointestinais e várias doenças ósseas e de articulações.

Cabe destacar que, o consumo de alimentos naturais, frescos e saudáveis surte efeitos positivos no organismo humano. Para Gomes (2007), ao ingerir uma boa variedade de frutas e hortaliças diariamente, além de fornecer ao organismo boas fontes de vitaminas, minerais e fibras, podem auxiliar na prevenção de DCNT's como o câncer e doenças cardiovasculares.

É fundamental lembrar também da importância de uma alimentação saudável para pessoas que estão fazendo dieta. Como afima Koehnlein et al (2008), ao dizerem que a inserção de frutas, hortaliças e cereais integrais [...] é de grande importância em associação com a restrição calórica na perda e manutenção do peso, uma vez que são alimentos ricos em fibras, que incorporados à dieta diminuem a ingestão energética aumentando a sensação de saciedade [...].

\footnotetext{
${ }^{1}$ Gordura saturada: está presente em alimentos de origem animal, é sólida à temperatura ambiente e seu consumo deve ser moderado. A Organização Mundial da Saúde (OMS) recomenda que não mais que $10 \%$ do total de energia consumida seja fornecida por esse tipo de gordura. BRASIL, 2005.
} 
Em resumo, de acordo com Bomtempo (2003), um estilo de vida saudável, que inclua uma alimentação com elevado teor de fibras e baixo teor de gorduras saturadas, associada a exercícios e ao uso do álcool com moderação, é capaz de reduzir drasticamente o risco de doenças do coração. Sendo assim, é importante destacar que: aumentar o consumo de frutas e hortaliças e estimular o consumo de arroz e feijão são exemplos simples de alimentação saudável, para prevenção das DCNTs e que estão ao alcance da sociedade como um todo (SICHIERI, et al, 2000).

De acordo com Canesqui e Garcia (2005), deve-se ressaltar que as escolhas alimentares não se fazem apenas com os alimentos considerados como os mais nutritivos, ou somente com os mais acessíveis e ofertados pela produção industrial. Segundo as autoras, a cultura, em um sentido mais amplo, molda a seleção alimentar, atribuindo normas que proíbem ou permitem o que comer.

Nesse sentido, nem sempre as pessoas têm idéia que se alimentam mal, muitas vezes fazem escolhas achando que são saudáveis. De acordo com Ramos (2005), apenas manter o peso ideal não significa ter hábitos alimentares corretos e estar consumindo todos os nutrientes necessários para uma dieta equilibrada.

Desse modo, um modelo de consumo alimentar equivocado pode ser revelado em uma situação de inquérito alimentar, não por falta de sinceridade, mas por incerteza entre o que a pessoa acha que come e o que realmente come, (GARCIA, 2004).

Contudo, para Toral e Slater (2007), existem dúvidas quanto aos reais meios que a população emprega para avaliar sua própria dieta e se as mudanças dietéticas realizadas para a adoção de hábitos saudáveis correspondem às recomendações dos guias alimentares.

Completando, segundo Garcia (2004), a veracidade da percepção do que se come também é um requisito importante para obter dados seguros do registro da ingestão alimentar. Segundo a autora, uma pessoa ao mencionar o que come, pode manifestar uma idealização de sua alimentação. Para Canesqui e Garcia (2005), os consumidores resumem as suas percepções mediante as idéias de autenticidade e qualidade.

Já se sabe da importância de uma alimentação saudável, completa, variada e agradável ao paladar para a promoção da saúde, e para a prevenção e controle de doenças crônicas não transmissíveis, cuja prevalência vem aumentando expressivamente (BOOG 1999). Como já mencionado anteriormente, de acordo com Ramalho e Saunders (2000), a escolha dos alimentos é complexa e influenciada por outros fatores além do acesso aos alimentos e o conhecimento de nutrição. Segundo os autores, embora se saiba que quando os alimentos não estão disponíveis é bem provável que ocorra deficiência, por outro lado, a 
abundância não garante boa nutrição devido ao componente comportamental que determina a preferência dos alimentos.

Para Santos (2005), no contexto da promoção das práticas alimentares saudáveis, a educação alimentar e nutricional é apontada como importante estratégia para enfrentar os novos desafios no campo da saúde, alimentação e nutrição.

Deve-se notar, todavia, que segundo Ramalho e Saunders (2000), apesar de a educação nutricional ser considerada como um esforço destinado a mudar os hábitos alimentares, padrões alimentares são determinados por fatores que incluem, além de educação orientada para uma nutrição adequada, fatores socioeconômicos, ecológicos, culturais e antropológicos. Para os autores, alguns destes fatores impedem, principalmente nas camadas mais carentes da população, a escolha correta de alimentos para uma dieta adequada.

Segundo Santos (2005), cabe destacar que o papel da educação alimentar e nutricional está ligado à produção de informações que sirvam como auxilio a tomada de decisões dos indivíduos que foram culpados pela sua ausência de conhecimento e que agora são chamados a ampliar o seu poder de escolha e decisão. Para o autor é imprescindível radicar a discussão sobre o papel da educação alimentar e nutricional dentro do contexto atual, e verificar qual seria a sua real contribuição para as novas demandas na promoção das práticas alimentares saudáveis. 


\section{IV-METODOLOGIA}

O presente trabalho de monografia de natureza transversal exploratório foi desenvolvido por meio de estudo quantitativo e por métodos e técnicas científicas como: revisão de literatura, seleção da amostra, coleta e análise dos dados.

A revisão de literatura foi realizada em língua portuguesa no período de agosto de 2008 a fevereiro de 2009, englobando a consulta a livros, artigos técnicos e científicos, trabalhos acadêmicos, sítios da internet e periódicos relevantes no tema objeto da pesquisa. As palavras chaves usadas na pesquisa de acordo com o tema do trabalho são: Alimentação Saudável, Práticas Alimentares e Educação Alimentar.

A coleta de dados ocorreu por meio da aplicação de formulários (Apêndice-I), constituído por dezesseis perguntas objetivas com opções de respostas especificas, que foram respondidas na ausência do pesquisador. Nesse formulário foram abordadas questões como: quantidade consumida de frutas e hortaliças, leguminosas, cereais, carnes, peixes, leite e derivados, doces e produtos industrializados, entre outras questões. O formulário foi fundamentado pelo Guia Alimentar (Brasil, 2006): Como ter uma Alimentação Saudável, o qual não sofreu nenhuma alteração em seu conteúdo e foi elaborado como parte de diretrizes acerca de hábitos alimentares saudáveis. Dos 47 formulários aplicados três foram excluídos por problemas no preenchimento completo desses. Assim a amostra final foi de 44 participantes sendo 37 do sexo feminino e 7 do sexo masculino.

O universo amostral abrangeu discentes matriculados no $2^{\circ}$ semestre de 2008 no Centro de Excelência em Turismo - CET, localizado na Universidade de Brasília - UNB nos cursos de: Qualidade em Alimentos (22 indivíduos), Gestão de Negócios em Turismo (12 indivíduos) e Gastronomia e Segurança Alimentar (10 indivíduos). Todos que aceitaram participar da pesquisas fizeram parte do universo.

Os resultados foram tabulados em forma de porcentagem e os dados coletados foram dispostos em forma de tabelas, quadro e figuras, com o objetivo de facilitar a compreensão do leitor. Os anexos I e II auxiliaram na tabulação dos dados e análise dos resultados e discussões.

A formação profissional prevalecente em cada turma avaliada também foi usada como forma de comparação na tabulação dos dados.

Como os alunos são provenientes de diferentes áreas de formação, os dados foram avaliados quanto a essas diferenças também. 


\section{RESULTADOS E DISCUSSÃO}

Dentre os cursos avaliados o perfil profissional dos estudantes é distribuído da seguinte forma:

Qualidade em Alimentos: 56\% Nutricionistas e os demais distribuídos entre, Economista Doméstica, Biólogos, Médicos Veterinários, Engenheiro de Alimentos, Tecnólogo de Alimentos, Químico e Pedagoga.

Gestão de Negócios em Turismo: 65,2\% Turismólogos, e os demais distribuídos entre, Administrador de Empresas, Advogados, Administrador em Turismo e Teólogo.

Gastronomia e Segurança Alimentar: 60\% Nutricionistas e os demais distribuídos entre, profissionais liberais e empresários.

De acordo com o Guia Alimentar brasileiro (2006), cada um dos grupos de alimentos tem um determinado número de porções a serem consumidas por dia e que para melhor entendimento devem ser consultadas no anexo I.

A Tabela 1 apresenta as recomendações do Guia Alimentar (BRASIL, 2006) e os resultados obtidos nas amostras avaliadas. 
Tabela 1: Recomendação do Guia Alimentar (BRASIL, 2006) e resultados obtidos nas amostras avaliadas

\begin{tabular}{|c|c|c|c|c|c|}
\hline & \multirow{2}{*}{$\begin{array}{c}\begin{array}{c}\text { Recomendação/ } \\
\text { Por dia }\end{array} \\
\text { Guia Alimentar } \\
\text { (BRASIL, 2006) } \\
\end{array}$} & \multicolumn{4}{|c|}{$\begin{array}{c}\text { Resultados das amostras avaliadas } \\
\text { Consumo / por dia }\end{array}$} \\
\hline & & Qualidade em Alimentos & Gestão de Negócios em Turismo & $\begin{array}{c}\text { Gastronomia e Segurança } \\
\text { Alimentar }\end{array}$ & \\
\hline Frutas & 3 porções ou mais & $\begin{array}{c}\text { Não como frutas, nem tomo suco de } \\
\text { frutas natural todos os dias } \\
\mathbf{4 , 5 \%} \\
1 \text { unidade/fatia/pedaço/copo de } \\
\text { suco natural } \\
\mathbf{4 5 , 5 \%} \\
2 \text { unidades/fatias/pedaços/copos de } \\
\text { suco natural } \\
\mathbf{3 1 , 8 \%} \\
\mathbf{3} \text { ou mais } \\
\text { unidades/fatias/pedaços/ copos de } \\
\text { suco natural } \\
\mathbf{1 8 , 2 \%}\end{array}$ & $\begin{array}{c}\text { Não como frutas, nem tomo suco } \\
\text { de frutas natural todos os dias } \\
\mathbf{2 5 \%} \\
1 \text { unidade/fatia/pedaço/copo de } \\
\text { suco natural } \\
\mathbf{4 1 , 7 \%} \\
2 \text { unidades/fatias/pedaços/copos } \\
\text { de suco natural } \\
\mathbf{1 6 , 7 \%} \\
\mathbf{3} \text { ou mais } \\
\text { unidades/fatias/pedaços/ copos } \\
\text { de suco natural } \\
\mathbf{1 6 , 7 \%}\end{array}$ & $\begin{array}{c}\text { Não como frutas, nem tomo suco de } \\
\text { frutas natural todos os dias } \\
\mathbf{1 0 \%} \\
1 \text { unidade/fatia/pedaço/copo de suco } \\
\text { natural } \\
\mathbf{2 0 \%} \\
2 \text { unidades/fatias/pedaços/copos de } \\
\text { suco natural } \\
\mathbf{1 0 \%} \\
\mathbf{3} \text { ou mais unidades/fatias/pedaços/ } \\
\text { copos de suco natural } \\
\mathbf{6 0 \%}\end{array}$ & $\begin{array}{l}\text { Consumo abaixo do } \\
\text { recomendado nas } \\
\text { amostras de } \\
\text { Qualidade em } \\
\text { Alimentos e } \\
\text { Gestão de Negócios } \\
\text { em Turismo }\end{array}$ \\
\hline Hortaliças & 3 porções & $\begin{array}{c}\text { Não como hortaliças todos os dias } \\
\mathbf{1 8 , 2 \%} \\
3 \text { ou menos colheres de sopa } \\
\mathbf{5 0 \%} \\
4 \text { a } 5 \text { colheres de sopa } \\
\mathbf{3 1 , 8 \%} \\
\mathbf{8} \text { ou mais colheres de sopa } \\
\mathbf{0 \%}\end{array}$ & \begin{tabular}{|c} 
Não como hortaliças todos os dias \\
$\mathbf{1 6 , 7 \%}$ \\
3 ou menos colheres de sopa \\
$\mathbf{3 3 , 3 \%}$ \\
4 a 5 colheres de sopa \\
$\mathbf{5 0 \%}$ \\
$\mathbf{8}$ ou mais colheres de sopa \\
$\mathbf{0 \%}$
\end{tabular} & $\begin{array}{c}\text { Não como hortaliças todos os dias } \\
\mathbf{2 0 \%} \\
3 \text { ou menos colheres de sopa } \\
\mathbf{0 \%} \\
4 \text { a } 5 \text { colheres de sopa } \\
\mathbf{6 0 \%} \\
\mathbf{8} \text { ou mais colheres de sopa } \\
\mathbf{2 0 \%}\end{array}$ & $\begin{array}{l}\text { Consumo abaixo do } \\
\text { recomendado }\end{array}$ \\
\hline Feijões & 1 porção & $\begin{array}{c}\text { Não consumo } \\
\mathbf{0 \%} \\
\text { Consumo menos de } 5 \text { vezes por } \\
\text { semana } \\
\mathbf{1 3 , 7 \%} \\
1 \text { colher de sopa ou menos por dia } \\
\mathbf{4 5 , 5 \%} \\
\mathbf{2} \text { ou mais colheres de sopa por } \\
\text { dia } \\
\mathbf{4 0 , 9 \%}\end{array}$ & \begin{tabular}{|c|} 
Não consumo \\
$\mathbf{0 \%}$ \\
Consumo menos de 5 vezes por \\
semana \\
$\mathbf{1 6 , 7 \%}$ \\
1 colher de sopa ou menos por dia \\
$\mathbf{3 3 , 3 \%}$ \\
$\mathbf{2}$ ou mais colheres de sopa por \\
dia \\
$\mathbf{5 0 \%}$
\end{tabular} & $\begin{array}{c}\text { Não consumo } \\
\mathbf{0 \%} \\
\text { Consumo menos de } 5 \text { vezes por } \\
\text { semana } \\
\mathbf{1 0 \%} \\
1 \text { colher de sopa ou menos por dia } \\
\mathbf{1 0 \%} \\
\mathbf{2} \text { ou mais colheres de sopa por dia } \\
\mathbf{8 0 \%}\end{array}$ & $\begin{array}{c}\text { Consumo } \\
\text { baixo na amostra de } \\
\text { Qualidade em } \\
\text { Alimentos }\end{array}$ \\
\hline
\end{tabular}




\begin{tabular}{|c|c|c|c|c|c|}
\hline & $\begin{array}{l}\text { Recomendação/ } \\
\text { Por dia }\end{array}$ & & $\begin{array}{r}\text { Resultados das amost } \\
\text { Consumo / po }\end{array}$ & $\begin{array}{l}\text { IS avaliadas } \\
\text { dia }\end{array}$ & \\
\hline & $\begin{array}{l}\text { Guia Alimentar } \\
\text { (BRASIL, 2006) }\end{array}$ & Qualidade em Alimentos & Gestão de Negócios em Turismo & $\begin{array}{c}\text { Gastronomia e Segurança } \\
\text { Alimentar }\end{array}$ & \\
\hline $\begin{array}{c}\text { Cereais } \\
\text { Tubérculos e } \\
\text { Raízes }\end{array}$ & 6 porções & $\begin{array}{l}1 \text { porção } 22,7 \% \\
2 \text { porções } 22,7 \% \\
3 \text { porções } 22,7 \% \\
\mathbf{4} \text { porções } \mathbf{1 8 , 2} \% \\
\mathbf{6} \text { porções } \mathbf{1 3 , 7 \%}\end{array}$ & $\begin{array}{c}1 \text { porção } 8,3 \% \\
2 \text { porções } 25 \% \\
3 \text { porções } 25 \% \\
\mathbf{4} \text { porções } \mathbf{1 6 , 7 \%} \\
\mathbf{5} \text { porções } 8,3 \% \\
\mathbf{7} \text { porções } \mathbf{1 6 , 7 \%} \\
\end{array}$ & $\begin{array}{l}1 \text { porção } 20 \% \\
2 \text { porções } 50 \% \\
3 \text { porções } 10 \% \\
\mathbf{4} \text { porções } 20 \%\end{array}$ & $\begin{array}{l}\text { Consumo abaixo do } \\
\text { recomendado }\end{array}$ \\
\hline $\begin{array}{c}\text { Carnes e } \\
\text { Ovos }\end{array}$ & 1 porção & $\begin{array}{c}\text { Não consumo nenhum tipo de carne } \\
\mathbf{4 , 5 \%} \\
1 \text { pedaço } \\
\mathbf{4 0 , 9 \%} \\
\mathbf{2} \text { pedaços } \\
\mathbf{4 0 , 9 \%} \\
\text { Mais de } 2 \text { pedaços } \\
\mathbf{1 3 , 6 \%}\end{array}$ & $\begin{array}{c}\text { Não consumo nenhum tipo de } \\
\text { carne } \\
\mathbf{0 \%} \\
1 \text { pedaço } \\
\mathbf{2 5 \%} \\
\mathbf{2} \text { pedaços } \\
\mathbf{5 8 \%} \\
\text { Mais de } 2 \text { pedaços } \\
\mathbf{1 6 , 7 \%} \\
\end{array}$ & $\begin{array}{c}\text { Não consumo nenhum tipo de carne } \\
\mathbf{1 0 \%} \\
1 \text { pedaço } \\
\mathbf{2 0 \%} \\
2 \text { pedaços } \\
\mathbf{5 0 \%} \\
\text { Mais de } 2 \text { pedaços } \\
\mathbf{2 0 \%}\end{array}$ & Alto consumo \\
\hline $\begin{array}{c}\text { Costume de } \\
\text { tirar a } \\
\text { gordura das } \\
\text { carnes }\end{array}$ & $\begin{array}{l}\text { Descartar toda } \\
\text { gordura aparente } \\
\text { das carnes }\end{array}$ & $\begin{array}{c}\text { Sim 86,4\% } \\
\text { Não } 13,7 \% \\
\text { Não como carne vermelha ou } \\
\text { frango } \\
\mathbf{0 \%}\end{array}$ & $\begin{array}{c}\text { Sim } \mathbf{7 5 \%} \\
\text { Não } 25 \% \\
\text { Não como carne vermelha ou } \\
\text { frango } \\
\mathbf{0 \%}\end{array}$ & $\begin{array}{c}\text { Sim } 80 \% \\
\text { Não } 10 \% \\
\text { Não como carne vermelha ou frango } \\
10 \%\end{array}$ & Consumo adequado \\
\hline Peixes & 2 vezes na semana & $\begin{array}{c}\text { Não consumo } \\
\mathbf{1 3 , 7 \%} \\
1 \text { a } 4 \text { vezes por mês } \\
\mathbf{2 7 , 3 \%} \\
\text { Algumas vezes no ano } \\
\mathbf{3 6 , 4 \%} \\
\mathbf{2} \text { ou mais vezes por semana } \\
\mathbf{2 2 , 7 \%}\end{array}$ & $\begin{array}{c}\text { Não consumo } \\
\mathbf{0 \%} \\
1 \text { a } 4 \text { vezes por mês } \\
\mathbf{4 1 , 7 \%} \\
\text { Algumas vezes no ano } \\
\mathbf{4 1 , 7 \%} \\
\mathbf{2} \text { ou mais vezes por semana } \\
\mathbf{1 6 , 7 \%}\end{array}$ & $\begin{array}{c}\text { Não consumo } \\
\mathbf{1 0 \%} \\
1 \text { a } 4 \text { vezes por mês } \\
\mathbf{5 0 \%} \\
\text { Algumas vezes no ano } \\
\mathbf{3 0 \%} \\
\mathbf{2} \text { ou mais vezes por semana } \mathbf{1 0 \%}\end{array}$ & $\begin{array}{l}\text { Consumo abaixo do } \\
\text { recomendado }\end{array}$ \\
\hline
\end{tabular}




\begin{tabular}{|c|c|c|c|c|c|}
\hline & $\begin{array}{l}\text { Recomendação/ } \\
\text { Por dia }\end{array}$ & & $\begin{array}{r}\text { Resultados das amost } \\
\text { Consumo / pe }\end{array}$ & $\begin{array}{l}\text { as avaliadas } \\
\text { dia }\end{array}$ & \\
\hline & $\begin{array}{l}\text { Guia Alimentar } \\
\text { (BRASIL, 2006) }\end{array}$ & Qualidade em Alimentos & Gestão de Negócios em Turismo & $\begin{array}{c}\text { Gastronomia e Segurança } \\
\text { Alimentar }\end{array}$ & \\
\hline $\begin{array}{c}\text { Tipo de } \\
\text { gordura usada }\end{array}$ & $\begin{array}{l}1 \text { porção, dando } \\
\text { preferência aos } \\
\text { óleos vegetais, } \\
\text { azeite e margarinas } \\
\text { livres de ácidos } \\
\text { graxos trans }\end{array}$ & $\begin{array}{c}\text { Banha animal ou manteiga } \\
\mathbf{0 \%} \\
\text { Óleo vegetal como: soja, girassol, } \\
\text { milho, algodão ou canola } \\
\mathbf{1 0 0 \%} \\
\text { Margarina ou gordura vegetal } \\
\mathbf{0 \%}\end{array}$ & $\begin{array}{c}\text { Banha animal ou manteiga } \\
\mathbf{0 \%} \\
\text { Óleo vegetal como: soja, girassol, } \\
\text { milho, algodão ou canola } \\
\mathbf{1 0 0 \%} \\
\text { Margarina ou gordura vegetal } \\
\mathbf{0 \%}\end{array}$ & $\begin{array}{c}\text { Banha animal ou manteiga } \\
\mathbf{0 \%} \\
\text { Óleo vegetal como: soja, girassol, } \\
\text { milho, algodão ou canola } \\
\mathbf{1 0 0 \%} \\
\text { Margarina ou gordura vegetal } \\
\mathbf{0 \%}\end{array}$ & $\begin{array}{c}\text { Não foi avaliado o } \\
\text { número de porções } \\
\text { Consumo satisfatório } \\
\text { nas amostras }\end{array}$ \\
\hline $\begin{array}{l}\text { Costume em } \\
\text { colocar mais } \\
\text { sal nos } \\
\text { alimentos } \\
\text { quando já } \\
\text { servidos no } \\
\text { prato } \\
\end{array}$ & $\begin{array}{l}5 \mathrm{~g} / \text { dia }(1 \text { colher } \\
\text { rasa de chá por } \\
\text { pessoa) }\end{array}$ & $\begin{array}{l}\operatorname{Sim} 4,5 \% \\
\text { Não 95,5\% }\end{array}$ & $\begin{array}{l}\text { Sim 16,7\% } \\
\text { Não } \mathbf{8 3 , 3 \%}\end{array}$ & $\begin{array}{l}\text { Sim 20\% } \\
\text { Não 80\% }\end{array}$ & $\begin{array}{l}\text { Não foi avaliado o } \\
\text { número de porções } \\
\text { Consumo satisfatório } \\
\text { nas } \\
\text { amostras }\end{array}$ \\
\hline Água & 8 copos ou mais & $\begin{array}{c}\text { Menos de } 4 \text { copos } \\
\mathbf{9 , 9 \%} \\
\mathbf{8} \text { copos ou mais } \\
\mathbf{3 1 , 8 \%} \\
4 \text { a } 5 \text { copos } \\
\mathbf{3 1 , 8 \%} \\
6 \text { a } 8 \text { copos } \\
\mathbf{2 7 , 3 \%}\end{array}$ & $\begin{array}{c}\text { Menos de } 4 \text { copos } \\
\mathbf{8 , 3 \%} \\
\mathbf{8} \text { copos ou mais } \\
\mathbf{5 0 \%} \\
4 \text { a } 5 \text { copos } \\
\mathbf{1 6 , 7 \%} \\
\text { 6 a } 8 \text { copos } \\
\mathbf{2 5 \%}\end{array}$ & $\begin{array}{c}\text { Menos de } 4 \text { copos } \\
\mathbf{3 0 \%} \\
\mathbf{8} \text { copos ou mais } \\
\text { 30\% } \\
4 \text { a } 5 \text { copos } \\
0 \% \\
\text { 6 a } 8 \text { copos } \\
\mathbf{4 0 \%}\end{array}$ & $\begin{array}{l}\text { Consumo abaixo do } \\
\text { recomendado }\end{array}$ \\
\hline $\begin{array}{l}\text { Costume de } \\
\quad \text { ler } \\
\text { informações } \\
\text { nutricionais } \\
\text { presentes nos } \\
\text { rótulos de } \\
\text { alimentos } \\
\text { industrializad } \\
\text { os antes de } \\
\text { comprá-los }\end{array}$ & $\begin{array}{c}\text { Discorre da } \\
\text { importância em ler } \\
\text { as informações } \\
\text { nutricionais e a } \\
\text { lista de ingredientes } \\
\text { contidas nos rótulos }\end{array}$ & $\begin{array}{c}\text { Nunca } \\
\mathbf{1 3 , 7 \%} \\
\text { Quase nunca } \\
\mathbf{3 1 , 8 \%} \\
\text { Algumas vezes, para alguns } \\
\text { produtos } \\
\mathbf{1 8 , 2 \%} \\
\text { Sempre ou quase sempre para } \\
\text { todos os produtos. } \\
\mathbf{3 6 , 4 \%}\end{array}$ & $\begin{array}{c}\text { Nunca } \\
\mathbf{8 , 3 \%} \\
\text { Quase nunca } \\
\mathbf{0 \%} \\
\text { Algumas vezes, para alguns } \\
\text { produtos } \\
\mathbf{3 3 , 3 \%} \\
\text { Sempre ou quase sempre para } \\
\text { todos os produtos. } \\
\mathbf{5 8 , 3 \%}\end{array}$ & $\begin{array}{c}\text { Nunca } \\
\mathbf{0 \%} \\
\text { Quase nunca } \\
\mathbf{1 0 \%} \\
\text { Algumas vezes, para alguns produtos } \\
\mathbf{5 0 \%} \\
\\
\text { Sempre ou quase sempre para } \\
\text { todos os produtos. } \\
\mathbf{4 0 \%}\end{array}$ & $\begin{array}{l}\text { Na amostra de } \\
\text { Gestão de } \\
\text { Negócios em } \\
\text { Turismo o } \\
\text { resultado foi o } \\
\text { mais satisfatório }\end{array}$ \\
\hline
\end{tabular}




\begin{tabular}{|c|c|c|c|c|c|}
\hline & \multirow{2}{*}{$\begin{array}{c}\begin{array}{c}\text { Recomendação/ } \\
\text { Por dia }\end{array} \\
\text { Guia Alimentar } \\
\text { (BRASIL, 2006) } \\
\end{array}$} & \multicolumn{4}{|c|}{$\begin{array}{c}\text { Resultados das amostras avaliadas } \\
\text { Consumo / por dia }\end{array}$} \\
\hline & & Qualidade em Alimentos & Gestão de Negócios em Turismo & $\begin{array}{c}\text { Gastronomia e Segurança } \\
\text { Alimentar }\end{array}$ & \\
\hline $\begin{array}{c}\text { Leites e } \\
\text { Derivados }\end{array}$ & 3 porções & $\begin{array}{c}\text { Não consumo } \\
\mathbf{0 \%} \\
1 \text { ou menos copos } \\
\mathbf{3 6 , 4 \%} \\
2 \text { copos } \\
\mathbf{5 4 , 5 4 \%} \\
\mathbf{3} \text { ou mais copos } \\
\mathbf{9 , 1 \%} \\
\end{array}$ & $\begin{array}{c}\text { Não consumo } \\
\mathbf{8 , 3 \%} \\
1 \text { ou menos copos } \\
\mathbf{5 8 , 3 \%} \\
2 \text { copos } \\
\mathbf{8 , 3 \%} \\
\mathbf{3} \text { ou mais copos } \\
\mathbf{2 5 \%} \\
\end{array}$ & $\begin{array}{c}\text { Não consumo } \\
\mathbf{0 \%} \\
1 \text { ou menos copos } \\
\mathbf{6 0 \%} \\
2 \text { copos } \\
\mathbf{4 0 \%} \\
\mathbf{3} \text { ou mais copos } \\
\mathbf{0 \%} \\
\end{array}$ & $\begin{array}{l}\text { Consumo abaixo do } \\
\text { recomendado }\end{array}$ \\
\hline $\begin{array}{l}\text { Tipo de leite } \\
\text { e derivados }\end{array}$ & $\begin{array}{l}\text { Adultos consumir } \\
\text { preferencialmente o } \\
\text { desnatado }\end{array}$ & $\begin{array}{c}\text { Integral } \\
\mathbf{5 9 , 1 \%} \\
\text { Semi-desnatado, desnatado ou light } \\
\mathbf{4 0 , 9 \%} \\
\text { Não consumo } \mathbf{0 \%} \\
\end{array}$ & $\begin{array}{c}\text { Integral } \\
\mathbf{5 0 \%} \\
\text { Semi-desnatado, desnatado ou } \\
\text { light } \\
\mathbf{4 1 , 7 \%} \\
\text { Não consumo } \mathbf{8 , 3 \%} \\
\end{array}$ & $\begin{array}{c}\text { Integral } \\
\mathbf{6 0 \%} \\
\text { Semi-desnatado, desnatado ou light } \\
\mathbf{4 0 \%} \\
\text { Não consumo } \mathbf{0 \%} \\
\end{array}$ & $\begin{array}{c}\text { Consumo } \\
\text { Inadequado }\end{array}$ \\
\hline $\begin{array}{c}\text { Frituras } \\
\text { hambúrgueres } \\
\text { presuntos e } \\
\text { embutidos }\end{array}$ & Evitar & $\begin{array}{c}\text { Raramente ou nunca } \\
\mathbf{9 , 1 \%} \\
\text { Todos os dias } \\
\mathbf{9 , 1 \%} \\
\text { De } 2 \text { a } 3 \text { vezes por semana } \\
\mathbf{4 5 , 5 \%} \\
\text { De } 4 \text { a } 5 \text { vezes por semana } \\
\mathbf{0 \%} \\
\text { Menos que } 2 \text { vezes por semana } \\
\mathbf{3 6 , 4 \%}\end{array}$ & $\begin{array}{c}\text { Raramente ou nunca } \\
\mathbf{1 6 , 7 \%} \\
\text { Todos os dias } \\
\mathbf{1 6 , 7 \%} \\
\text { De } 2 \text { a } 3 \text { vezes por semana } \\
\mathbf{3 3 , 3 \%} \\
\text { De } 4 \text { a } 5 \text { vezes por semana } \\
\mathbf{8 , 3 \%} \\
\text { Menos que } 2 \text { vezes por semana } \\
\mathbf{2 5 \%}\end{array}$ & $\begin{array}{c}\text { Raramente ou nunca } \\
\mathbf{6 0 \%} \\
\text { Todos os dias } \\
\mathbf{0 \%} \\
\text { De } \mathbf{2} \text { a } \mathbf{3} \text { vezes por semana } \\
\mathbf{2 0 \%} \\
\text { De } 4 \text { a } 5 \text { vezes por semana } \\
\mathbf{1 0 \%} \\
\text { Menos que } 2 \text { vezes por semana } \mathbf{1 0 \%}\end{array}$ & $\begin{array}{l}\text { Não foi avaliado o } \\
\text { número de porções }\end{array}$ \\
\hline $\begin{array}{c}\text { Doces de } \\
\text { qualquer tipo }\end{array}$ & $\begin{array}{c}1 \text { porção sendo } \\
\text { menos que } 3 \text { vezes } \\
\text { por semana }\end{array}$ & $\begin{array}{c}\text { Raramente ou nunca } \\
\mathbf{2 2 , 7 \%} \\
\text { Todos os dias } \\
\mathbf{1 3 , 7 \%} \\
\text { De } 2 \text { a } 3 \text { vezes por semana } \\
\mathbf{4 5 , 5 \%} \\
\text { De } 4 \text { a } 5 \text { vezes por semana } \\
\mathbf{1 8 , 2 \%}\end{array}$ & $\begin{array}{c}\text { Raramente ou nunca } \\
\mathbf{1 6 , 7 \%} \\
\text { Todos os dias } \\
\mathbf{2 5 \%} \\
\text { De } 2 \text { a } 3 \text { vezes por semana } \\
\mathbf{3 3 , 3 \%} \\
\text { De } 4 \text { a } 5 \text { vezes por semana } \\
\mathbf{2 5 \%}\end{array}$ & $\begin{array}{c}\text { Raramente ou nunca } \\
\mathbf{5 0 \%} \\
\text { Todos os dias } \\
\mathbf{2 0 \%} \\
\text { De } 2 \text { a } 3 \text { vezes por semana } \\
\mathbf{3 0 \%} \\
\text { De } 4 \text { a } 5 \text { vezes por semana } \\
\mathbf{0 \%}\end{array}$ & $\begin{array}{c}\text { Não foi avaliado o } \\
\text { número de porções } \\
\text { Consumo satisfatório } \\
\text { nas amostras }\end{array}$ \\
\hline
\end{tabular}




\begin{tabular}{|c|c|c|c|c|c|}
\hline & \multirow{2}{*}{$\begin{array}{c}\begin{array}{c}\text { Recomendação/ } \\
\text { Por dia }\end{array} \\
\text { Guia Alimentar } \\
\text { (BRASIL, 2006) } \\
\end{array}$} & \multicolumn{4}{|c|}{$\begin{array}{l}\text { Resultados das amostras avaliadas } \\
\text { Consumo / por dia }\end{array}$} \\
\hline & & Qualidade em Alimentos & Gestão de Negócios em Turismo & $\begin{array}{c}\text { Gastronomia e Segurança } \\
\text { Alimentar }\end{array}$ & \\
\hline $\begin{array}{l}\text { Número de } \\
\text { refeições } \\
\text { habitualmente } \\
\text { feitas durante } \\
\quad \text { o dia }\end{array}$ & $\begin{array}{l}3 \text { refeições (café da } \\
\text { manhã, almoço e } \\
\text { jantar), intercalados } \\
\text { por pequenos } \\
\text { lanches. }\end{array}$ & $\begin{array}{l}\text { 81,8\% consomem o café da manhã } \\
\mathbf{3 1 , 8 \%} \text { consomem o lanche da } \\
\text { manhã }\end{array}$ & $\begin{array}{c}\text { 66,7\% consomem o café da } \\
\text { manhã } \\
\mathbf{2 5 \%} \text { consomem o lanche da } \\
\text { manhã }\end{array}$ & $\begin{array}{l}90 \% \text { consomem o café da manhã } \\
50 \% \text { consomem o lanche da manhã } \\
100 \% \text { consomem o almoço } \\
\begin{array}{c}70 \% \text { consomem o lanche ou café da } \\
\text { tarde }\end{array} \\
\begin{array}{c}90 \% \text { consomem o jantar ou café da } \\
\text { noite }\end{array} \\
60 \% \text { consomem o lanche antes de } \\
\text { dormir }\end{array}$ & $\begin{array}{c}\text { Consumo baixo nos } \\
\text { lanches da manhã e } \\
\text { antes de dormir nas } \\
\text { amostras de } \\
\text { Qualidade em } \\
\text { Alimentos e } \\
\text { Gestão de Negócios } \\
\text { em Turismo }\end{array}$ \\
\hline
\end{tabular}


Em relação à quantidade de frutas (unidade/fatia/pedaço/copo de suco natural) ingeridas por dia pelos estudantes, 11,4\% não consomem frutas, nem toma suco de fruta natural, 27,3\% consomem três ou mais unidades/fatias/pedaços/copos de suco natural, 22,7\% consomem duas unidades/fatias/pedaços/copos de suco natural e 38,6\% consomem uma unidade/fatia/pedaço/copo de suco natural.

Como mostra a Tabela 1, a pesquisa registrou que em relação à quantidade de frutas (unidade/fatia/pedaço/copo de suco natural) ingeridas por dia pelos estudantes, apenas a turma de Gastronomia e Segurança Alimentar teve um consumo satisfatório onde 60\% ingerem três ou mais unidades/ fatias/pedaços/copos de suco natural por dia.

Uma provável justificativa para um maior consumo de frutas incidir na turma de Gastronomia e Segurança Alimentar pode ser pelo fato de 60\% da amostra ser composta por nutricionistas. Já na amostra do curso de Qualidade em Alimentos, onde 56\% também são nutricionistas o consumo não foi satisfatório.

Em relação à quantidade de hortaliças (não foram considerados nesse grupo os tubérculos e as raízes como: batata, mandioca, inhame, cará), ingeridas pelos estudantes, 18,2 \% não consomem hortaliças todos os dias, 34,1\% ingerem três ou menos colheres de sopa, $43,2 \%$ consomem de quatro a cinco colheres de sopa e $4,5 \%$ consomem oito ou mais colheres de sopa.

Observa-se, de acordo com a Tabela 1, consumo abaixo do recomendado para todos os cursos onde, $0 \%$ dos alunos do curso de Qualidade em Alimentos, $0 \%$ dos alunos do curso de Gestão de Negócios em Turismo e 20\% do curso de Gastronomia e Segurança Alimentar consomem oito ou mais colheres de sopa por dia de hortaliças.

Para o Guia Alimentar do Brasil (2006), frutas e hortaliças são ricas em vitaminas, minerais e fibras e devem estar presentes em todas as refeições e lanches realizados no decorrer do dia, pois ajudam na proteção à saúde. Desse modo, o consumo deve ser diário sendo, três porções de hortaliças e três porções ou mais de frutas nas refeições (Anexo - I).

Segundo Bleil (1998), nota-se que alimentos in natura como as hortaliças e as frutas continuam com consumo reduzido: apenas $44 \%$ dos brasileiros dizem comer frutas e $58 \%$, hortaliças. Essa informação está de acordo com Pesquisa de Orçamentos Familiares do IBGE2002/2003 ao revelar que, em geral, as famílias brasileiras consomem muitos alimentos com alto teor de açúcar, principalmente refrigerantes, e poucas quantidades de frutas e hortaliças.

Ainda segundo a POF (IBGE, 2004), em relação aos grupos hortaliças e frutas, a região Sul obteve as maiores quantidades adquiridas (39 kg e $31 \mathrm{~kg}$, respectivamente). O Norte $(20 \mathrm{~kg})$ apresentou a menor aquisição per capita de hortaliças, bem abaixo da média 
nacional $(29 \mathrm{~kg})$ e das regiões Sudeste $(32 \mathrm{~kg})$, Centro-Oeste $(23 \mathrm{~kg})$ e Nordeste $(22 \mathrm{~kg})$. Quanto às frutas, o menor consumo foi do Centro-Oeste $(17 \mathrm{~kg})$, seguido de perto pelo Norte $(18 \mathrm{~kg})$.

Em relação à quantidade de feijão de qualquer tipo ou cor, lentilha, ervilha, grão-debico, soja, fava, sementes ou castanhas ingeridas por dia pelos estudantes, 52,3\% consomem duas ou mais colheres de sopa, $13,6 \%$ consomem menos de cinco vezes por semana e $34,1 \%$ ingerem uma colher de sopa ou menos por dia.

De acordo com a tabela 1, 80\% dos alunos do curso de Gastronomia e Segurança Alimentar, 50\%, dos alunos do curso de Gestão de Negócios em Turismo, consomem duas ou mais colheres de sopa por dia e 40,1\% dos alunos do curso de Qualidade em Alimentos consomem duas ou mais colheres de sopa. Para o Guia Alimentar Brasil (2006), o consumo diário deve ser de uma porção de leguminosas (feijões) que corresponde a duas colheres de sopa .

Mondini e Monteiro (1994) descrevem redução do consumo de cereais e derivados, feijão, raízes e tubérculos, observados, principalmente, da década de 70 para a década de 80 .

Segundo a POF de 2002/2003 (IBGE, 2004), quanto maior a renda, menor o consumo domiciliar por pessoa de cereais, leguminosas, farinhas, féculas e massas. Ainda de acordo com a POF, a pesquisa mostra que tem diminuído o consumo de produtos tradicionais como arroz, feijão, batata, pão e açúcar e aumentado, por exemplo, o consumo per capita de iogurte, que passou de $0,4 \mathrm{~kg}$ para $2,9 \mathrm{~kg}$.

Observa-se na Tabela 1 que em nenhuma das três amostras analisadas os resultados se aproximam do recomendado para cereais. Para o Guia Alimentar Brasil (2006), o consumo diário de alimentos ricos em carboidratos complexos (amidos), como cereais, de preferência integrais, tubérculos e raízes, deve ser de seis porções (Anexo - I e II).

Segundo a POF de 2002/2003 (IBGE, 2004), os resultados mostram que famílias que ganham mais, tendem a consumir um maior teor de gorduras e menor de carboidratos. De acordo com a mesma pesquisa, alguns alimentos se destacam na relação com os rendimentos, como o arroz, cujo consumo diminui na medida em que aumenta a renda das famílias. $\mathrm{O}$ contrário acontece com pães e biscoitos, cuja participação na dieta tende a aumentar com o aumento dos rendimentos.

Mondini e Monteiro (1994) observam uma menor contribuição dos carboidratos no consumo calórico total e a sua substituição por gorduras, principalmente da década de 70 para a década de 80 . 
Em relação à quantidade de carnes (gado, porco, aves, peixes e outras) ou ovos ingeridos por dia pelos estudantes, 4,5\% não consomem nenhum tipo de carne, 31,8\% consomem um pedaço/fatia/colher de sopa ou um ovo, 47,7 ingerem dois pedaços/fatias/colheres de sopa ou dois ovos, 15,9\% consomem mais de dois pedaços/fatias/colheres de sopa ou mais de dois ovos. Observa-se um consumo acima do recomendado nos três cursos pesquisados, como mostra a Tabela 1.

De acordo com o Guia Alimentar brasileiro (2006), o consumo diário de carnes, peixes ou ovos deve ser de uma porção (Anexo - I) e sempre com baixo teor de gordura. Charque e derivados de carne (salsicha, lingüiça, presuntos e outros embutidos) contêm, em geral, excesso de gorduras e sal e somente devem ser consumidos ocasionalmente.

Segundo Bleil (1998), houve um aumento na quantidade de proteína ingerida, com uma diminuição na quantidade dos carboidratos. Essa informação está de acordo com Mondini e Monteiro (1994), ao dizer que houve um aumento no consumo de carnes, principalmente a partir da segunda metade da década de 70 . De acordo com a POF de 2002/2003 (IBGE, 2004), embora o teor de proteínas na dieta aumente conforme a renda, a proporção de calorias protéicas foi adequada em todas as classes de rendimento. Destaca-se, ainda, que a fração de proteínas de origem animal (de maior valor biológico) consumidas aumenta com a renda, variando de $45 \%$ na faixa menor a $60 \%$ na maior. Notou-se que $81,8 \%$ dos estudantes têm o costume de tirar a gordura aparente das carnes, a pele do frango ou outro tipo de ave, $15,9 \%$ não o fazem e 2,3\% não comem carne vermelha ou frango. De acordo com o Guia Alimentar brasileiro (2006), toda a gordura aparente das carnes e a pele das aves devem ser descartadas.

A pesquisa mostra que a maioria dos discentes dos três cursos analisados tem o costume de tirar a gordura aparente das carnes, a pele do frango ou outro tipo de ave.

Em relação ao costume de comer peixes, observa-se um baixo consumo onde, 9,1\% não consomem, 36,4\% consomem somente algumas vezes no ano, 18,2\% consomem duas ou mais vezes por semana e 36,4\% consomem de uma a quatro vezes por mês. Vale ressaltar que para o Guia Alimentar brasileiro (2006), uma boa opção que deve ser estimulada é o consumo de peixes, pois contêm proteínas de alto valor biológico e gorduras insaturadas ${ }^{2}$ que não são

\footnotetext{
${ }^{2}$ Gorduras insaturadas: dividem-se em dois tipos: monoinsaturadas e poliinsaturadas. Ao contrário das gorduras saturadas, as insaturadas não causam problemas de saúde, exceto quando consumidas em grande quantidade.

Ácidos Graxos Monoinsaturados: as principais fontes são azeite de oliva, óleos vegetais (girassol, canola e arroz), azeitona, abacate e oleaginosas (castanhas, nozes, amêndoas).

Ácidos Graxos Poliinsaturados: as principais fontes são os óleos vegetais (óleos de algodão, milho, soja, girassol e de linhaça) e óleo de peixe. BRASIL, 2005.
} 
prejudiciais à saúde. O consumo de peixe fresco deve ser de pelo menos duas vezes por semana.

Em relação ao costume de comer peixes, observa-se um baixo consumo nos três cursos avaliados.

Segundo a POF de 2002/2003 (IBGE, 2004), o consumo de pescados fica em torno de $6 \mathrm{~kg}$ nos rendimentos mais baixos e em torno de $4 \mathrm{~kg}$ nos rendimentos mais altos. Os pescados de água doce são a principal influência para este comportamento do grupo (em torno de $3 \mathrm{~kg}$ nos rendimentos mais baixos e menor que $1 \mathrm{~kg}$ nos mais altos).

Em relação à quantidade de leite e seus derivados (iogurtes, bebidas lácteas, coalhada, requeijão, queijos e outros) consumidos pelos estudantes, 2,3\% não consomem leite, nem derivados, 11,4\% consomem três ou mais copos de leite ou pedaços/fatias/porções, $38,6 \%$ consomem dois copos de leite ou pedaços/fatias/porções e 47,7\% consomem um ou menos copos de leite ou pedaços/fatias/porções.

Para o Guia Alimentar brasileiro (2006), o consumo diário de leite e derivados deve ser de três porções (Anexo -I). Leite e derivados são boas fontes de proteínas, vitaminas e cálcio, nutriente fundamental para a formação e manutenção da massa óssea. Entretanto nos últimos anos o consumo diário de leite vem sofrendo redução como indica os dados da POF de 2002/2003 (IBGE, 2004). Dados levantados pela pesquisa mostram que o consumo do leite de vaca pasteurizado apresentou grande variação passando de 62,4 kg em 1987 para 38 kg, em 2002/03, as aquisições de leite caíram quase 40\%, mas mantendo-o como o produto adquirido em maior quantidade pelas famílias pesquisadas.

A pesquisa mostra um consumo abaixo do recomendado e ao mesmo tempo inadequado onde, 54,5\% o consomem na forma integral, 43,2\% consomem o semi-desnatado, desnatado ou light e 2,3\% não consomem leite e derivados. De acordo com o Guia Alimentar Brasil (2006), a escolha deve ser de produtos que contenham menor teor de gordura. O leite e seus derivados, para adultos que já completaram seu crescimento, devem ser preferencialmente desnatados.

Observa-se que no curso de Gastronomia e Segurança Alimentar, onde 60\% são nutricionistas e no curso de Qualidade em Alimentos, onde 56\% também são nutricionistas, esse percentual de $60 \%$ e 59,1\% (Tabela 1), respectivamente, consumirem leite integral não condiz com o conhecimento dos alunos, em razão de sua formação acadêmica.

Em relação à quantidade de frituras, salgadinhos fritos ou em pacotes, carnes salgadas, hambúrgueres, presuntos e embutidos (salsicha, mortadela, salame, lingüiça e 
outros), ingeridos pelos estudantes, 22,7\% consomem raramente ou nunca, 9,1\% consomem todos os dias, $36,4 \%$ consomem de duas a três vezes por semana, $27,3 \%$ consomem menos que duas vezes por semana e 4,5\% consomem de quatro a cinco vezes por semana.

Mais uma vez o fato dos alunos do curso de Gastronomia e Segurança Alimentar ser composto por $60 \%$ de nutricionista pode ter influenciado positivamente a amostra, sugerindo um consumo mais consciente, como indicam os dados da pesquisa. Já na amostra do curso de Qualidade em Alimentos, onde 56\% também são nutricionistas o consumo não foi tão satisfatório.

Os resultados das amostras estão de acordo com o Guia Alimentar brasileiro (2006), que discorre da importância em haver uma redução no consumo de alimentos com alta concentração de gordura, sal e açúcar, visando diminuir o risco da ocorrência de obesidade, hipertensão arterial, diabetes, e doenças cardiovasculares.

Dados da POF de 2002/2003 (IBGE, 2004), apontam que no caso das gorduras, observou-se que o limite máximo de $30 \%$ das calorias totais é ultrapassado nas famílias com renda acima de dois salários-mínimos mensal familiar per capita. As gorduras saturadas tendem a aumentar ainda mais intensamente com o rendimento do que as demais gorduras, sendo que o limite máximo para este componente da dieta ( $10 \%$ das calorias totais) é virtualmente alcançado pelas famílias que ganham entre dois e cinco salários mínimos $(9,7 \%)$ e claramente ultrapassado entre os que ganham mais de cinco salários-mínimos per capita (11,2\% das calorias totais).

Em relação à quantidade de doces de qualquer tipo, bolos recheados com cobertura, e biscoitos doces, refrigerantes e sucos industrializados, ingeridos pelos estudantes, 27,3\% consomem raramente ou nunca, 18,2\% consomem todos os dias, 36,4\% ingerem de duas a três vezes por semana e 18,2\% consomem de quatro a cinco vezes por semana.

Como mostra a Tabela 1, o consumo de doces de qualquer tipo, bolos recheados com cobertura, e biscoitos doces, refrigerantes e sucos industrializados, ingeridos pelos estudantes, está dentro do recomendado, nas amostras analisadas. De acordo com o Guia Alimentar brasileiro (2006), o consumo máximo diário deve ser de uma porção de alimentos do grupo dos açúcares e doces sendo, menos que três vezes por semana. Ainda segundo informações do Guia (2006), deve-se evitar bolos, biscoitos doces, sobremesas e doces como regra da alimentação, preferindo aqueles preparados em casa, com óleos vegetais. Refrigerantes, bebidas industrializadas, doces e produtos de confeitaria contêm muito açúcar e favorecem o aparecimento de cáries, sobrepeso, obesidade, e não são considerados saudáveis. 
Segundo a POF de 2002/2003 (IBGE, 2004), o limite máximo de 10\% para a proporção de calorias provenientes de açúcar é ultrapassado em todas as classes de rendimentos, notando-se que a situação mais crítica corresponde às classes intermediárias de rendimentos, onde a participação deste componente da dieta alcança quase $15 \%$.

Em relação ao tipo de gordura mais usada em casa para cozinhar os alimentos notouse que, $100 \%$ dos entrevistados, alunos dos cursos de Gastronomia e Segurança Alimentar, Qualidade em Alimentos e Gestão de Negócios em Turismo, usam óleo vegetal como: soja, girassol, milho, algodão ou canola.

Essa constatação aponta mudança de hábito conforme identificado por Mondini e Monteiro (1994), em pesquisa onde avaliaram o comportamento do padrão alimentar da população urbana brasileira ao longo de três décadas. Nessa pesquisa os autores verificaram que houve uma substituição da banha, bacon e manteiga por óleos vegetais e margarina.

De acordo com o Guia Alimentar brasileiro (2006), o consumo máximo diário deve ser de uma porção de alimentos do grupo dos óleos e gorduras, dando preferência aos óleos vegetais, azeite e margarinas livres de ácidos graxos trans. ${ }^{3}$

Em relação ao hábito de colocar mais sal nos alimentos já servidos no prato $11,4 \%$ o fazem e $88,6 \%$ não o fazem.

De acordo com o Guia Alimentar brasileiro (2006), a quantidade de sal por dia deve ser de no máximo, uma colher de chá rasa por pessoa $(5 \mathrm{~g})$, distribuídas em todas as preparações consumidas durante o dia. Isso significa que o consumo atual médio de sal pela população deve ser reduzido à metade. $\mathrm{O}$ sal deve ser sempre iodado e o uso do saleiro à mesa deve ser evitado. Ainda segundo informações do Guia (2006), deve-se reduzir o consumo de alimentos processados com alta concentração de sal, como temperos prontos, caldos concentrados, molhos prontos, salgadinhos, sopas industrializadas e outros.

Em relação freqüência de refeições feitas durante o dia pelos discentes, 79,5\% consomem o café da manhã, 34,1\% consomem o lanche da manhã, $100 \%$ consomem o almoço, $61,4 \%$ o lanche ou café da tarde, $65,9 \%$ o jantar ou café da noite e 45,5\% consomem o lanche antes de dormir.

A pesquisa pode mostrar mais uma vez que o fato dos discentes do curso de Gastronomia e Segurança Alimentar ser composto de $60 \%$ de nutricionista pode estar

\footnotetext{
3 Ácidos graxos trans: é um tipo de gordura obtida do processo de industrialização de alimentos, a partir da hidrogenação de óleos vegetais. A hidrogenação converte os óleos vegetais líquidos e insaturados em gorduras sólidas e mais estáveis à temperatura ambiente, produzindo um tipo de gordura conhecida como ácidos graxos trans ou gordura trans. BRASIL, 2005.
} 
influenciado nesse caso para um consumo mais adequado. Em contra partida, a pesquisa mais uma vez mostra também que na amostra do curso de Qualidade em Alimentos onde $56 \%$ dos alunos são nutricionistas os resultados não são tão satisfatórios.

De acordo com o Guia Alimentar brasileiro (2006), para garantir a saúde o correto é fazer, pelo menos, três refeições por dia (café da manhã, almoço e jantar), intercalados por pequenos lanches.

Em relação ao consumo de água ingerida por dia, incluindo sucos de frutas naturais ou chás (exceto café, chá preto e chá mate), 13,6\% ingerem menos de quatro copos, 36,4\% consomem oito copos ou mais (um número muito pequeno, menos da metade dos estudantes), $20,5 \%$ consomem quatro a cinco copos e $29,5 \%$ consomem de seis a oito copos.

Sendo os discentes do curso de Gastronomia e Segurança Alimentar composto por 60\% de nutricionistas e no curso de Qualidade em Alimentos composto de 56\% também de nutricionistas, esse percentual de apenas $30 \%$ e $31,8 \%$ respectivamente, consumirem oito copos ou mais de líquidos além de ser considerado um percentual muito baixo, não condiz com a formação dos alunos.

Segundo o Guia Alimentar brasileiro (2006), as pessoas devem ingerir no mínimo dois litros de água por dia (seis a oito copos), preferencialmente entre as refeições. Essa quantidade pode variar de acordo com a atividade física e com a temperatura do ambiente. A água deverá ser sempre tratada ou fervida e filtrada, para beber e para preparar refeições e sucos.

Em relação ao costume de ler a informação nutricional presente no rótulo de alimentos industrializados antes de comprá-los, 9,1\% nunca o faz, 18,2\% quase nunca o faz, $29,5 \%$ o faz algumas vezes, para alguns produtos e $43,2 \%$ o faz sempre ou quase sempre para todos os produtos.

Mais uma vez cabe fazer uma ressalva na amostra do curso de Gastronomia e Segurança Alimentar (composta por $60 \%$ de nutricionista) que não apresentaram resultados satisfatórios, pois apenas $40 \%$ dos alunos têm o costume de ler sempre ou quase sempre a informação nutricional presente no rótulo de alimentos industrializados antes de comprá-los. Já no curso de Qualidade em Alimentos (composto por 56\% de nutricionistas), esse percentual é de apenas $36,4 \%$.

Vale destacar que o Guia Alimentar brasileiro (2006) discorre da importância em ler as informações nutricionais e a lista de ingredientes contidas nos rótulos e da sua correta interpretação, buscando sempre a aquisição de alimentos mais saudáveis. 


\section{VI-CONCLUSÃO}

A realização desse trabalho permitiu observar que só a informação não é suficiente para adoção de práticas alimentares saudáveis. Mesmo grande parte dos discentes tendo formação superior em nutrição e estarem cursando pós-graduação, o que se trata de um público que tem acesso à informação de qualidade, não garante escolhas alimentares corretas e adoção a práticas saudáveis.

Os resultados dessa pesquisa sugerem que para os discentes fazerem escolhas nutricionais corretas é necessário ampliar o conhecimento sobre alimentação saudável, buscando fazer a seleção dos alimentos de forma adequada.

A amostra que teve mais resultados satisfatórios foi a dos discentes do curso de Gastronomia e Segurança Alimentar, embora o que prevaleceu nessa amostra e nas demais foi a não adequação da recomendação do consumo diário estabelecida pelo Guia Alimentar (Brasil, 2006). Esse resultado pode ter ocorrido pelo fato do curso de Gastronomia e Segurança Alimentar ter $60 \%$ de nutricionistas. Embora a maior parte dos discentes do curso de Qualidade em Alimentos também serem nutricionistas, 56\%, essa amostra não obteve resultados adequados na maioria das questões. Como hábitos e práticas demoram um tempo para serem alterados, pode ser que o tempo de formação dos nutricionistas seja uma causa para diferença, ou até mesmo, a não preocupação desse grupo com a dieta saudável. Os profissionais de saúde precisam ser treinados para atuarem como educadores de terceiros e de si próprio, incentivando a formação de práticas alimentares saudáveis, dando uma preciosa contribuição para a saúde pública e favorecendo para uma melhor qualidade de vida.

Conclui-se que para possibilitar a adoção de hábitos e práticas alimentares saudáveis é importante ampliar as atividades educativas junto à população com base em informações científicas e em políticas públicas. O Guia Alimentar para População Brasileira é um bom exemplo de incentivo do governo na busca pela promoção da saúde. 


\section{VII-REFERÊNCIAS}

ARAÚJO, W.M.C.; BOTELHO, R.A.; GINANI, V; ARAÚJO, H.M.C.; ZANDONADI, R.P. Da Alimentação à Gastronomia. Brasília: Ed. UNB, 2005. 102p.

ASSIS, M. A. A.; NAHAS, M. V. Aspectos motivacionais em programas de mudança de comportamento alimentar. Revista de Nutrição. Campinas, 12(1): 33-41, 1999.

AZEVEDO, E. Alimentos Orgânicos: Ampliando os Conceitos de Saúde Humana, Ambiental e Social. Florianópolis: Insular, 2003. 200p.

BLEIL, S. I. O Padrão Alimentar Ocidental: considerações sobre a mudança de hábitos no Brasil. Revista Cadernos de Debate. UNICAMP, São Paulo, 1998.

BOOG, M. C. F. Educação nutricional em serviços públicos de saúde. Caderno de Saúde Pública. Rio de Janeiro, vol.15 suppl.2, 1999.

BRASIL, Guia Alimentar para a População Brasileira: Série A. Normas e Manuais Técnicos. Ministério da Saúde, Secretária da Atenção à Saúde, Coordenação-Geral da Política de Alimentação e Nutrição. Brasília, DF, 2005. 284p.

BRASIL, Guia Alimentar para a População Brasileira: Promovendo a Alimentação Saudável. Ministério da Saúde, Secretária da Atenção à Saúde, Coordenação-Geral da Política de Alimentação e Nutrição. Brasília, DF, 2006. 210p.

BRASIL, Guia Alimentar: Como ter uma alimentação saudável. Ministério da Saúde, Secretária da Atenção à Saúde, Coordenação-Geral da Política de Alimentação e Nutrição. Brasília, DF, 2006. 31p.

BONTEMPO, M. Alimentação para um Novo Mundo. Rio de Janeiro: Record, 2003. 313p.

BOTELHO, R.A. Culinária Regional: o Nordeste e a Alimentação Saudável. Dissertação de Doutorado (Doutora em Ciências da Saúde) Universidade de Brasília, Brasília, 2006. 188p.

CANESQUI, A. M., GARCIA, R. W. D., Organizadoras. Antropologia e Nutrição: um diálogo possível - Antropologia e Saúde. Ed. FIOCRUZ. Rio de Janeiro, outubro de 2005.

CERVATO, A. M. ; DERNTL. A. M. ; LATORRE, M. do R. D. de O. ; MARUCCI, M. de F. N. Educação nutricional para adultos e idosos:uma experiência positiva em Universidade. Revista de Nutrição. Campinas, 2005.

COTA, R. P. ; MIRANDA, L. S. Associação entre constipação intestinal e estilo de vida em estudantes Universitários. Revista Brasileira de Nutrição Clínica. Campinas, 21(4):296301, 2006.

FREITAS, M do C. S. de. ; PENA, P. G. L. Segurança Alimentar e Nutricional: a produção do conhecimento com ênfase nos aspectos da cultura. Revista de Nutrição, Campinas, 20(1), 2007. 
GARCIA, R. W. D. Representações sobre consumo alimentar e suas implicações em inquéritos alimentares: estudo qualitativo em sujeitos submetidos à prescrição dietética. Revista de Nutrição. Campinas, vol.17(1), 2004.

GARCIA, R. W. D. Reflexos da globalização na cultura alimentar: considerações sobre as mudanças na alimentação urbana. Revista de Nutrição. Campinas. 16(4):483-492, 2003.

GARCIA, R. W. D. Práticas e comportamento alimentar no meio urbano: um estudo no centro da cidade de São Paulo.Caderno de Saúde Pública. Rio de Janeiro, vol.13(3), 1997.

GINANI, V. Índice de Aceitação de Preparações Regionais com Teor Lipídico Modificado. Dissertação de Mestrado (Mestre em Nutrição Humana) Universidade de Brasília, Brasília, 2004. 148p.

GOMES, F. da S. Frutas, legumes e verduras: recomendações técnicas versus constructos sociais. Revista de Nutrição. Campinas, 20(6) 669-680, 2007.

INSTITUTO BRASILEIRO DE GEOGRAFIA E ESTATÍSTICA (IBGE). Pesquisa de Orçamento Familiar de 2002/2003. Rio de Janeiro, 2004. Disponível em http://www.ibge.gov.br>Acesso em janeiro de 2009.

JOMORI, M. M.; PROENÇA, R. P. da C.; CALVO, M. C. M. Determinantes de escolha alimentar. Revista de Nutrição. Campinas, 21(1), 2008.

KOEHNLEIN, E. A.; SALADO, G. A ; YAMADA, A. N. Adesão à reeducação alimentar para perda de peso: determinantes, resultados e a percepção do paciente. Revista Brasileira de Nutrição Clínica. Campinas, 23(1):56-65, 2008.

MONDINI, L.; MONTEIRO, C. A. Mudanças no padrão de alimentação da população urbana brasileira (1962-1988). Revista de Saúde Pública. São Paulo, 28:433-9, 1994.

OLIVEIRA, J. E. D. de. Educação e direito à alimentação. Estudos Avançados, 2007.

PINHEIRO, A. R. de O. A alimentação saudável e a promoção da saúde no contexto da Revista do CEBES : Saúde em Debate, Rio de Janeiro, 29(70):125-139,2005.

PINHEIRO, R. Hábitos Alimentares: gestão essencial para uma vida produtiva e saudável. Salvador, BA: Casa da Qualidade, 1999. 142p.

POUBEL, R. de O. Hábitos Alimentares, Nutrição e Sustentabilidade: Agroflorestas Sucessionais como Estratégia na Agricultura Familiar. Dissertação de Mestrado (Mestre em Desenvolvimento Sustentável) Universidade de Brasília, Brasília, 2006. 136p.

RAMALHO, R. A., SAUNDERS. C. O papel da educação nutricional no combate às carências nutricionais. Revista de Nutrição. Campinas, 13(1): 11-16, 2000.

RAMOS, S. R. Avaliação do Estado Nutricional de Universitários. Dissertação de mestrado (Mestre em Ciência de Alimentos) Faculdade de Farmácia da UFMG, Belo Horizonte, 2005. 109p. 
SANTOS, L. A. da S. Educação alimentar e nutricional no contexto da promoção de práticas alimentares saudáveis. Revista de Nutrição. Campinas, 18(5):681-692, 2005.

SICHIERI, R. COITINHO D. C. MONTEIRO, J. B. COUTINHO, W. F. Recomendações de Alimentação e Nutrição Saudável para a População Brasileira. Arquivos Brasileiros Endocrinologia Metabologia. São Paulo, 44(3): 227-232, 2000.

SLOAN, D. Gastronomia, Restaurantes e Comportamento do Consumidor. Barueri, SP: Manole, 2005. 221p.

TARDIO, A. P. ; FALCÃO, M. C. O impacto da modernização na transição nutricional e obesidade. Revista Brasileira de Nutrição Clínica. Campinas, 21(2):117-24, 2006.

TORAL, N.; SLATER, B. Abordagem do modelo transteórico no comportamento alimentar Ciência \& Saúde Coletiva. São Paulo, 12(6):1641-1650, 2007. 
ANEXO - I
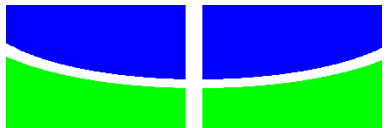

\section{Universidade de Brasília \\ CET - Centro de Excelência em Turismo \\ Pós-graduação Lato Sensu}

Curso de Especialização em Qualidade em Alimentos

Essa pesquisa faz parte da elaboração de monografia de Joseane Lima Ferreira Lelis, aluna do curso de Especialização em Qualidade em Alimentos. Gostaria de sua colaboração nas respostas desse formulário que segue abaixo. Por favor, responda-o levando em consideração o que realmente você come e não o que gostaria ou acha que seria melhor. Escolha apenas UMA RESPOSTA.

Obrigada pela participação

\section{Identificação:}

Sexo: Feminino ( ) Masculino ( )

\section{Curso:}

1) Qual é, em média, a quantidade de frutas (unidade/fatia/pedaço/copo de suco natural) que você come por dia?

a. ( ) Não como frutas, nem tomo suco de frutas natural todos os dias

b. ( ) 3 ou mais unidades/fatias/pedaços/copos de suco natural

c. ( ) 2 unidades/fatias/pedaços/copos de suco natural

d. ( ) 1 unidade/fatia/pedaço/copo de suco natural

2) Qual é, em média, a quantidade hortaliças que você come por dia?

Atenção! Não considere nesse grupo os tubérculos e as raízes (Ex: batata, mandioca, inhame, cará)

a. ( ) Não como hortaliças todos os dias

b. ( ) 3 ou menos colheres de sopa

c. ( ) 4 - 5 colheres de sopa

d. ( ) 8 mais colheres de sopa

3) Qual é, em média, a quantidade que você come dos seguintes alimentos: feijão de qualquer tipo ou cor, lentilha, ervilha, grão-de-bico, soja, fava, sementes ou castanhas?
a. ( ) Não consumo
b. ( ) 2 ou mais colheres de sopa por dia
c. ( ) Consumo menos de 5 vezes por semana
d. ( ) 1 colher de sopa ou menos por dia 
4) Qual a quantidade, em média, que você consome por dia dos alimentos listados abaixo?

a. Arroz, milho e outros cereais (inclusive os matinais); mandioca/macaxeira/aipim, cará ou inhame; macarrão e outras massas; batata-inglesa, batata-doce, batata-baroa ou mandioquinha:

b. Pães: colheres de sopa

c. Bolos sem cobertura e/ou recheio: fatias

d. Biscoito ou bolacha sem recheio: unidades

5) Qual é, em média, a quantidade de carnes (gado, porco, aves, peixes e outras) ou ovos que você come por dia?

a. ( ) Não consumo nenhum tipo de carne

b. ( ) 1 pedaço/fatia/colher de sopa ou 1 ovo

c. ( ) 2 pedaços/fatias/colheres de sopa ou 2 ovos

d. ( ) Mais de 2 pedaços/fatias/colheres de sopa ou mais de 2 ovos

6) Você costuma tirar a gordura aparente das carnes, a pele do frango ou outro tipo de ave?
a. ( ) $\operatorname{Sim}$
b. ( ) Não
c. ( ) Não como carne vermelha ou frango

7) Você costuma comer peixes com qual freqüência?

a. ( ) Não consumo

b. ( ) Somente algumas vezes no ano

c. ( ) 2 ou mais vezes por semana

d. ( ) De 1 a 4 vezes por mês

8) Qual é, em média, a quantidade de leite e seus derivados (iogurtes, bebidas lácteas, coalhada, requeijão, queijos e outros) que você come por dia?

Pense na quantidade usual que você consome: pedaço, fatia ou porções em colheres de sopa ou copo grande (tamanho do copo de requeijão) ou xícara grande, quando for o caso.

a. ( ) Não consumo leite, nem derivados

b. ( ) 3 ou mais copos de leite ou pedaços/fatias/porções

c. ( ) 2 copos de leite ou pedaços/fatias/porções

d. ( ) 1 ou menos copos de leite ou pedaços/fatias/porções

9) Que tipo de leite e seus derivados você habitualmente consome?

a. ( ) Integral

b. ( ) Com baixo teor de gorduras (semi-desnatado, desnatado ou light)

c. ( ) Não consumo leite, nem derivados 
10) Pense nos seguintes alimentos: frituras, salgadinhos fritos ou em pacotes, carnes salgadas, hambúrgueres, presuntos e embutidos (salsicha, mortadela, salame, linguiiça e outros). Você costuma comer qualquer um deles com que freqüiência?
a. ( ) Raramente ou nunca
b. ( ) Todos os dias
c. ( ) De 2 a 3 vezes por semana
d. ( ) De 4 a 5 vezes por semana
e. ( ) Menos que 2 vezes por semana

11) Pense nos seguintes alimentos: doces de qualquer tipo, bolos recheados com cobertura, e biscoitos doces, refrigerantes e sucos industrializados. Você costuma comer qualquer um deles com que frequiência?
a. ( ) Raramente ou nunca
b. ( ) Todos os dias
c. ( ) De 2 a 3 vezes por semana
d. ( ) De 4 a 5 vezes por semana

12) Qual tipo de gordura é mais usada na sua casa para cozinhar os alimentos?

a. ( ) Banha animal ou manteiga

b. ( ) Óleo vegetal como: soja, girassol, milho, algodão ou canola

c. ( ) Margarina ou gordura vegetal

13) Você costuma colocar mais sal nos alimentos quando já servidos em seu prato?
a. ( ) $\operatorname{Sim}$
b. ( ) Não

14) Pense na sua rotina semanal: quais as refeições você costuma fazer habitualmente no dia?

\begin{tabular}{|l|l|l|}
\hline & Não & Sim \\
\hline Café da manhã & & \\
\hline Lanche da manhã & & \\
\hline Almoço & & \\
\hline $\begin{array}{l}\text { Lanche ou café da } \\
\text { tarde }\end{array}$ & & \\
\hline Jantar ou café da noite & & \\
\hline $\begin{array}{l}\text { Lanche antes de } \\
\text { dormir }\end{array}$ & & \\
\hline
\end{tabular}

15) Quantos copos de água você bebe por dia? Inclua no seu cálculo sucos de frutas naturais ou chás (exceto café, chá preto e chá mate).
a. ( ) Menos de 4 copos
b. ( ) 8 copos ou mais
c. ( ) 4 a 5 copos
d. ( ) 6 a 8 copos 
16) Você costuma ler a informação nutricional que está presente no rótulo de alimentos industrializados antes de comprá-los?
a. ( ) Nunca
b. ( ) Quase nunca
c. ( ) Algumas vezes, para alguns produtos
d. ( ) Sempre ou quase sempre para todos os produtos. 


\section{ANEXO - II}

De acordo com o Guia Alimentar brasileiro (2006), cada um dos grupos de alimentos tem um determinado número de porções a serem consumidas por dia. As tabelas que seguem apresentam, para cada grupo, o valor calórico médio de uma porção, exemplos de alimentos e as medidas caseiras.

As porções foram distribuídas para um plano alimentar de 2.000 calorias por dia, quantidade média necessária para uma pessoa adulta saudável. Essa quantidade pode variar de acordo com a necessidade de cada pessoa, dependendo do seu peso, altura, sexo, idade e também de acordo com suas atividades.

Arroz, pães, massas, batata e mandioca - consuma seis porções ao dia (uma porção = 150 kcal)

\begin{tabular}{|l|l|}
\hline Alimentos & Uma porção equivale a \\
\hline Arroz branco cozido & 4 colheres de sopa \\
\hline Batata cozida & 1 e $1 / 2$ unidade \\
\hline Biscoito tipo “cream cracker" & 5 unidades \\
\hline Bolo de milho & 1 fatia \\
\hline Cereal matinal & 1 xícara de chá \\
\hline Farinha de mandioca & 2 colheres de sopa \\
\hline Macarrão cozido & $3 \mathrm{e}^{1 / 2}$ colheres de sopa \\
\hline Milho verde em espiga & 1 espiga grande \\
\hline Pão de forma tradicional & 2 fatias \\
\hline Pão francês & 1 unidade \\
\hline Purê de batata & 3 colheres de sopa \\
\hline Torrada salgada & 4 unidades \\
\hline
\end{tabular}

Hortaliças - consuma três porções ao dia (uma porção $=15 \mathrm{Kcal}$ )

\begin{tabular}{|l|l|}
\hline Alimentos & Uma porção equivale a \\
\hline Abóbora cozida & 1 e $1 / 2$ colher de sopa \\
\hline Alface & 15 folhas \\
\hline Beterraba crua ralada & 2 colheres de sopa \\
\hline Brócolis cozido & 4 e $1 / 2$ colheres de sopa \\
\hline Cenoura crua (picada) & 1 colher de servir \\
\hline Pepino picado & 4 colheres de sopa \\
\hline
\end{tabular}


Frutas - consuma três porções ao dia (uma porção $=70 \mathrm{kcal})$

\begin{tabular}{|l|l|}
\hline Alimentos & Uma porção equivale a \\
\hline Abacaxi & 1 fatia \\
\hline Ameixa-preta seca & 3 unidades \\
\hline Banana-prata & 1 unidade \\
\hline Caqui & 1 unidade \\
\hline Goiaba & $1 / 2$ unidade \\
\hline Laranja-pêra & 1 unidade \\
\hline Maçã & 1 unidade \\
\hline Mamão-papaia & $1 / 2$ unidade \\
\hline Melancia & 2 fatias \\
\hline $\begin{array}{l}\text { Salada de frutas (banana, maçã, laranja, } \\
\text { mamão) }\end{array}$ & $1 / 2$ xícara de chá \\
\hline Suco de laranja (puro) & $1 / 2$ copo de requeijão \\
\hline Tangerina/mexerica & 1 unidade \\
\hline Uva comum & 22 uvas \\
\hline
\end{tabular}

Feijões - consuma uma porção ao dia (uma porção $=55 \mathrm{kcal}$ )

\begin{tabular}{|l|l|}
\hline Alimentos & Uma porção equivale a \\
\hline Ervilha seca cozida & 2 e $1 / 2$ colheres de sopa \\
\hline Feijão cozido $(50 \%$ de caldo) & 1 concha \\
\hline Lentilha cozida & 2 colheres de sopa \\
\hline Soja cozida & 1 colher de servir \\
\hline
\end{tabular}

Carnes, peixes e ovos - consuma uma porção ao dia (uma porção $=190 \mathrm{kcal}$ )

\begin{tabular}{|l|l|}
\hline Alimentos & Uma porção equivale a \\
\hline Bife grelhado & 1 unidade \\
\hline Carne assada & 1 fatia pequena \\
\hline Frango/Filé grelhado & 1 unidade \\
\hline Omelete simples & 1 unidade \\
\hline Peixe-espada cozido & 1 porção \\
\hline
\end{tabular}

Leites, queijos, iogurtes - consuma três porções ao dia (uma porção $=120 \mathrm{kcal}$ )

\begin{tabular}{|l|l|}
\hline Alimentos & Uma porção equivale a \\
\hline Iogurte desnatado de frutas & 1 pote \\
\hline Iogurte integral natural & 1 copo de requeijão \\
\hline Leite tipo C & 1 copo de requeijão \\
\hline Queijo tipo minas frescal & 1 fatia grande \\
\hline Queijo tipo mussarela & 3 fatias \\
\hline
\end{tabular}


Óleos e gorduras - consuma uma porção ao dia (uma porção = 73 kcal)

\begin{tabular}{|l|l|}
\hline Alimentos & Uma porção equivale a \\
\hline Azeite de oliva & 1 colher de sopa \\
\hline Manteiga & $1 / 2$ colher de sopa \\
\hline Margarina vegetal & $1 / 2$ colher de sopa \\
\hline Óleo vegetal & 1 colher de sopa \\
\hline
\end{tabular}

Açúcares e doces - consuma no máximo uma porção ao dia (uma porção = $110 \mathrm{kcal}$ )

\begin{tabular}{|l|l|}
\hline Alimentos & Uma porção equivale a \\
\hline Açúcar cristal & 1 colher de sopa \\
\hline Geléia de frutas & 1 colher de sopa \\
\hline Mel & 2 e $1 / 2$ colheres de sopa \\
\hline
\end{tabular}




\section{ANEXO - III}

Calculo usado para tabulação da quarta questão.

Para saber o número de porções consumidas, divida essas quantidades pelo equivalente a 1 porção, conforme o exemplo:

Cálculo: número de porções consumidas dividido pelo equivalente a uma porção é igual a quantidade consumida

\section{Exemplo:}

\begin{tabular}{|c|c|c|c|}
\hline & $\begin{array}{c}\text { Quantidade } \\
\text { consumida }\end{array}$ & $\begin{array}{c}\text { Equivalente a uma } \\
\text { porção }\end{array}$ & $\begin{array}{c}\text { Número de porções } \\
\text { consumidas }\end{array}$ \\
\hline a & 9 colheres de sopa & 3 colheres de sopa & $9 \div 3=3$ \\
\hline b & 4 fatias & 1 unidade/2 fatias & $4 \div 2=2$ \\
\hline c & 0 fatia & 1 fatia & $0 \div 1=0$ \\
\hline d & 6 unidades & 6 unidades & $6 \div 6=1$ \\
\hline
\end{tabular}

Soma das porções consumidas $=\mathbf{3}+\mathbf{2}+\mathbf{0}+\mathbf{1}=\mathbf{6}$ porções

Cálculo a ser feito:

\begin{tabular}{|c|c|c|c|}
\hline & $\begin{array}{c}\text { Quantidade } \\
\text { consumida }\end{array}$ & $\begin{array}{c}\text { Equivalente a uma } \\
\text { porção }\end{array}$ & $\begin{array}{c}\text { Número de porções } \\
\text { consumidas }\end{array}$ \\
\hline a & Colhere(s) de sopa & 3 colheres de sopa & \\
\hline b & Fatia(s) & 1 unidade/2 fatias & \\
\hline c & Fatia(s) & 1 fatia & \\
\hline d & unidades & 6 unidades & \\
\hline
\end{tabular}

Soma das porções consumidas $=\mathbf{a}+\mathbf{b}+\mathbf{c}+\mathbf{d}=$ porções 